\title{
Resistance of tropical seedlings to drought is mediated by neighbourhood diversity
}

O’Brien, Michael J ; Reynolds, Glen ; Ong, Robert ; Hector, Andy

DOI: https://doi.org/10.1038/s41559-017-0326-0

Posted at the Zurich Open Repository and Archive, University of Zurich ZORA URL: https://doi.org/10.5167/uzh-140576

Journal Article

Accepted Version

Originally published at:

O'Brien, Michael J; Reynolds, Glen; Ong, Robert; Hector, Andy (2017). Resistance of tropical seedlings to drought is mediated by neighbourhood diversity. Nature Ecology and Evolution, 1(11):1643-1648.

DOI: https://doi.org/10.1038/s41559-017-0326-0 
1 Resistance of tropical seedlings to drought is mediated by neighbourhood diversity

2 Michael J. O’Brien ${ }^{1,2,3}$, Glen Reynolds ${ }^{2}$, Robert Ong ${ }^{4}$ and Andy Hector ${ }^{5}$

$3 \quad$ IEstación Experimental de Zonas Áridas, Consejo Superior de Investigaciones Científicas,

4 Carretera de Sacramento s/n, E-04120 La Cañada, Almería, Spain

$5 \quad{ }^{2}$ Southeast Asia Rainforest Research Partnership, Danum Valley Field Centre, PO Box

6 60282, 91112 Lahad Datu, Sabah, Malaysia

$7 \quad{ }^{3}$ URPP Global Change and Biodiversity, University of Zurich, Winterthurerstr. 190, 8057

8 Zurich, Switzerland

$9 \quad{ }^{4}$ Forest Research Centre, Sepilok, 90715 Sandakan, Sabah, Malaysia

$10 \quad{ }^{5}$ Department of Plant Sciences, University of Oxford, OXI 3RB UK

11 *Correspondence author e-mail: mikey.j.obrien@gmail.com

12 Title: 82 characters

13 Abstract: 201

14 Main: 1999

15 Refs: 40

16 Figures: 4 

change is increasing drought frequency and intensity in many areas across the globe threatening the structure and functioning of these ecosystems. However, the effects of intermittent drought on tropical tree communities remain poorly understood and the potential impacts of intensified drought under future climatic conditions are even less well known. The response of forests to altered precipitation will be determined by the

tolerances of different species to reduced water availability and the interactions among plants that alleviate or exacerbate the effects of drought. Here we report the response of experimental monocultures and mixtures of tropical trees to simulated drought that reveal a fundamental shift in the nature of interactions among species. Weaker competition for water in diverse communities allowed seedlings to maintain growth under drought while more intense competition among conspecifics inhibited growth under the same conditions. These results show that reduced competition for water among species in mixtures mediates community resistance to drought. The delayed onset of competition for water among species in more diverse neighbourhoods during drought has potential implications for the coexistence of species in tropical forests and the resilience of these systems to climate change.

Many types of tropical forests are characterized by constant temperature and humidity, typically experiencing regular rainfall evenly distributed throughout the year. However, rain forests often experience infrequent droughts, during El Niño Southern Oscillation (ENSO) years for example, although the effect of these events on forest structure and functioning is poorly understood ${ }^{1,2}$. On the one hand, drought could increase the success of some species putting them at an advantage, increasing dominance and potentially decreasing diversity ${ }^{3}$. Alternatively, drought could promote diversity by enhancing densitydependent mechanisms that favour uncommon species ${ }^{4}$. For example, drought may increase 
42 intraspecific competition for light, water and associated soil resources or predispose trees to

43 pathogen infection or insect attack ${ }^{5-7}$, both density-dependent mechanisms that can influence

44 community diversity ${ }^{8-10}$.

45 Although light is usually considered the most important resource gradient driving

46 species distributions in tropical forests ${ }^{7}$, climate change is projected to increase the severity

47 and frequency of drought for substantial areas of tropical forest ${ }^{1,11}$ thereby increasing the

48 importance of water limitation as a driver of species distributions ${ }^{12}$. These changes pose a

49 potential risk to these hyper-diverse ecosystems due to negative effects on reproduction ${ }^{13}$,

50 recruitment ${ }^{13}$, growth ${ }^{3,14}$ and survival ${ }^{3,15}$. Species diversity may provide an insurance effect

51 against these alterations and provide stability under drought conditions ${ }^{16,17}$ because species

52 vary in their resistance and resilience to severe climatic disturbances ${ }^{3,18}$. Although, if

53 conditions go beyond the physiological limits of even the tolerant species, then large-scale

54 mortality will occur regardless ${ }^{19}$. However, there is limited empirical evidence regarding the

55 direction and magnitude of the interactions between drought and tree diversity as research has

56 largely focused on shifts of species distributions and functional composition ${ }^{12,15,20}$.

$57 \quad$ Here we test how drought affects interactions among tropical tree seedlings in

58 monocultures and mixtures of different species. We used rainfall-exclusion shelters to reduce

59 soil water availability while altering tree seedling diversity by manipulating neighbourhood

60 richness around focal individuals (Fig. 1). Ecological theory predicts that competition for

61 limited resources is more intense when species and individuals are more similar and closely

62 related ${ }^{21,22}$. Therefore, neighbourhood diversity consisted of three treatments in which a focal

63 individual was surrounded by 3 individuals of the same, or 3 different, species as follows: 1)

64 a focal seedling surrounded by seedlings of 3 different species than those used as the focal

65 species (mixtures), 2) monocultures of a focal seedling surrounded by 3 seedlings originating

66 from a different mature tree of the same species (non-sibling) and 3) monocultures of a focal 
67 seedling surrounded by 3 seedlings originating from the same mature tree as the focal

68 seedling (sibling). The third neighbourhood represents the dense aggregated seedling

69 communities that form under mature trees after mast seed production, a common

70 reproductive strategy in these ever-wet tropical forests ${ }^{23}$. We used the rainfall-exclusion

71 shelters for two intervals lasting 3 and 6 months over a two-year period in order to simulate

72 drought intensity similar to supra-annual droughts in Malaysian Borneo ${ }^{24}$ (Fig. 2). We

73 monitored focal seedling growth and mortality and quantified the magnitude of drought

74 response in leaf physiology while assessing nutrient concentrations to test if drought

75 increased competition for water and nutrients.

\section{Results}

77 We found an interaction between the drought and diversity treatments in which the

78 strength of competition was related to seedling neighbourhood diversity under drought but

79 not ever-wet conditions (Fig. 3a). Specifically, in the monocultures (i.e. sibling and non-

80 sibling treatments) relative growth rate (RGR) was significantly lower in the drought than in

81 the ever-wet treatments, but seedlings in mixtures had RGRs that were statistically

82 indistinguishable under drought and ever-wet conditions (Fig. 3b; Supplementary Table 1).

83 These results are consistent with reduced competition for water in species mixtures relative to

84 monocultures. Furthermore, average RGR over all species under drought was higher in

85 mixtures than in monocultures (reduction in RGR due to non-sibling competition $=-0.06 \mathrm{~cm}$

$86 \mathrm{~cm}^{-1} \mathrm{yr}^{-1},-0.1$ to -0.02 and reduction in RGR due to sibling competition $=-0.04 \mathrm{~cm} \mathrm{~cm}^{-1} \mathrm{yr}^{-1}$,

$87-0.07$ to 0.003$)$. These results indicate that overall mixtures and monocultures are

88 significantly different under drought (see significant contrast $\times$ rainfall term in

89 Supplementary Table 1), but the sibling treatment is only marginally different from the

90 mixture (see neighbor $\times$ rainfall term in Supplementary Table 1). Although mortality was not 
91 severe (only $3 \%$ of the focal seedlings died), $80 \%$ of mortality occurred in the drought

92 treatment.

Measurements of seedling physiology support intensified competition for water as the

94 cause of lower growth rates in monocultures during drought. Our experimental drought

95 caused seedlings in all neighbourhoods to close their stomata to levels of $44 \%$ conductance

96 (95\% CI: $35-55)$ of seedlings in ever-wet conditions (Fig. 4a; Supplementary Table 2).

97 Therefore, seedlings in all neighbourhoods were responding to drier soils — at levels similar

98 to seedlings after approximately $70-100$ days of no water in a dry-down pot experiment ${ }^{25}$

99 (Supplementary Fig. 1). Despite all neighbourhoods showing reduced (but not completely

100 inhibited) stomatal conductance, leaf water potentials were significantly different among

101 neighbourhoods under drought. Leaf water potentials of focal seedlings were only

102 significantly lower in the drought than the ever-wet treatment in the non-sibling (reduction in

103 leaf water potential due to drought $=-0.3 \mathrm{MPa}, 95 \% \mathrm{CI}$ : -0.4 to -0.2 ) and sibling (reduction in

104 leaf water potential due to drought $=-0.2 \mathrm{MPa}, 95 \% \mathrm{CI}:-0.3$ to -0.1 ) neighbourhoods (Fig.

105 4b). Conversely, the leaf water potential of focal seedlings in mixture neighbourhoods was

106 statistically indistinguishable in the drought and ever-wet treatments (reduction in leaf water

107 potential due to drought $=-0.03 \mathrm{MPa}, 95 \% \mathrm{CI}:-0.1-0.1)$. In addition, under drought,

108 seedlings in monoculture neighbourhoods had significantly lower leaf water potential than

109 seedlings in mixtures (reduction in leaf water potential due to non-siblings $=-0.2 \mathrm{MPa}, 95 \%$

$110 \mathrm{CI}:-0.3$ to -0.1 and siblings $=-0.1 \mathrm{MPa}, 95 \% \mathrm{CI}:-0.2$ to -0.02$)$. These results indicate that

111 competition for water was more intense between individuals of the same species than among

112 seedlings of different species, which may be due to different rooting strategies or water use

113 efficiencies that produce complementarity in mixtures ${ }^{26}$.

114 Discussion 
Two pathways to reduced plant growth under drought have been suggested: carbon

116 limitation due to stomatal closure ${ }^{27}$ and sink limitation (i.e. limited water or nutrient

117 availability) that inhibits plant function and decouples growth and photosynthesis ${ }^{28,29}$.

118 Previous research indicates that dipterocarps continue to photosynthesize during drought

119 leading to accumulated nonstructural carbohydrates but eventually hydraulic failure ${ }^{25,30-32}$.

120 Our results support the hypothesis that the mechanism limiting growth during drought — and

121 eventually leading to mortality with increased drought severity - is water limitation that

122 inhibits cell expansion or division and not carbon limitation due to stomatal closure ${ }^{28-30}$.

123 Furthermore, although drought could also affect the availability or uptake of other soil

124 resources, leaf nitrogen and phosphorus concentrations and N:P ratio ${ }^{33}$ were statistically

125 indistinguishable among all levels of competition and water availability (Supplementary Fig.

1262 and Supplementary Table 3), which indicates competition for nutrients was similar among

127 all neighbourhoods. The incomplete closure of stomata, the reduced leaf water potentials in

128 monocultures and the lack of differences in leaf nutrients suggest that focal seedlings in

129 diverse mixtures had delayed water limitation during drought (and not carbon or nutrients)

130 thereby maintaining higher relative growth rates. In contrast, seedling growth in

131 monocultures became more quickly limited by water during drought.

132 Surprisingly, under ever-wet conditions, growth of the focal seedlings was statistically

133 indistinguishable among the three levels of diversity (Fig. 3a). Comparison of these growth

134 rates with those of seedlings grown for two years at low density without competition in a

135 nearby experiment ${ }^{3}$ showed that RGR was reduced by about 38\% (Fig. 3a). Competition -

136 for resources other than water - appears to have had strong negative effects on seedling

137 growth in general, but the effect was independent of diversity under ever-wet conditions,

138 consistent with small differences among species at the seedling stage in an ever-wet

139 climate $^{34}$. More unexpectedly, our results suggest that intermittent drought induces 
competition for water among conspecifics, which raises the possibility that ENSO events may promote coexistence. Previous work has investigated the role of differences in species tolerance of drought — usually inferred through differences in drought-induced mortality — in determining their spatial distribution in tropical forests ${ }^{12}$ and shifts in functional composition in response to drought ${ }^{20}$. However, our results lead us to hypothesize a potential stabilizing role of competition for water during intermittent drought — a type of hydrological realized niche - which may act as another driver of species distributions, in conjunction to and interacting with heterogeneity in light and nutrients ${ }^{7,35}$.

Non-sibling and sibling neighbourhoods had similar effects on focal seedling growth. We did not observe competitive differences at the genotypic level (i.e. the contrast of mixtures versus monocultures explained the most variation among neighbourhoods). Instead, responses were mainly at the species level (Supplementary Fig. 3) and between mixtures and monocultures (see the significant species $\times$ contrast $\times$ rainfall term in Supplementary Table 1). Our diversity treatment was designed to vary genetic similarity of seedlings in a threelevel gradient from most similar (siblings) to intermediate (non-siblings) to most dissimilar (mixtures), but the lack of effect between the sibling and non-sibling treatments could be explained by insufficient genetic dissimilarity among seed sources. For example, a high degree of out-crossing and long-distance pollen dispersal among mature trees would reduce variability among seed sources ${ }^{36}$.

Our results are based on seedling responses under experimental conditions and require comparison with existing and future data from natural droughts. To impose competition our experiment required relatively high seedling densities, although these were within the range of seedling densities 4 years after a mast fruiting event, e.g. $3-75$ seedlings $\mathrm{m}^{-2}$. We used mid-day leaf water potential as an indicator of water limitation. The use of pre-dawn leaf water potential or loss of hydraulic conductivity may have provided more direct means of 
assessing water limitations on growth since mid-day water limitation can be overcome with diurnal refilling (although it might be expected that the recovery of water potential during the day would require greater refilling than in the pre-dawn period). Supra-annual ENSO droughts in our study system normally last for between 1 and 3 months ${ }^{37}$. In our experiment, rainfall-exclusion shelters were maintained for as much as 6 months to induce soil drying during natural tropical rainfall, which caused water movement through the soil and higher cloud cover and humidity than would be the case during an ENSO event. However, this application achieved soil water potentials similar to and slightly greater than an ENSO drought $^{24}$.

Seedling dynamics and recruitment into the sapling stage are an important process that influences the future structure and composition of the forest ${ }^{3,38,39}$, and drought is likely to play a more prominent role in mediating those dynamics under climate change scenarios. Although these results at the seedling level have implications for future forest canopies, they may not directly relate to interactions among adult trees. In addition, tropical forest diversity is far greater than the number of species used in this experimental manipulation. However, the species were selected to encompass the range of functional traits found in the natural forest (Supplementary Fig. 4), and these species showed highly variable responses to both water availability and neighbourhood diversity that cannot be solely explained by $\operatorname{traits}^{40}$. Further research on drought responses of adult trees and more diverse tropical forest communities in general are needed to improve our understanding of the implications of a changing climate for this important ecosystem.

Our results have implications for two related areas of ecology. Our experimental demonstration of reduced competition for water among seedlings in diverse neighbourhoods suggests that intermittent drought may be a process that promotes and maintains diversity in these tropical rain forests as it has been shown to in a prairie grassland ${ }^{4}$. At the same time, 
our findings of differential responses of species to drought and of complementarity (reduced competition) among species in mixtures are consistent with the idea that diversity can also increase the resistance and stability of ecosystem functioning to extreme climatic events ${ }^{3}$. Interestingly, this suggests that intermittent drought may promote tree diversity in tropical forests, which in turn increases the resilience of the system to these drier conditions.

\section{References}

1. Chadwick, R., Good, P., Martin, G. \& Rowell, D. P. Large rainfall changes consistently projected over substantial areas of tropical land. Nat. Clim. Chang. 6, 177-181 (2015).

2. Cai, W. et al. Increasing frequency of extreme El Niño events due to greenhouse warming. Nat. Clim. Chang. 5, 1-6 (2014).

3. O’Brien, M. J., Ong, R. \& Reynolds, G. Intra-annual plasticity of growth mediates drought resilience over multiple years in tropical seedling communities. Glob. Chang. Biol. doi, 10.1111/gcb.13658 (2017).

4. Adler, P. B., HilleRisLambers, J., Kyriakidis, P. C., Guan, Q. \& Levine, J. M. Climate variability has a stabilizing effect on the coexistence of prairie grasses. Proc. Natl. Acad. Sci. 103, 12793-12798 (2006).

5. Bagchi, R. et al. Pathogens and insect herbivores drive rainforest plant diversity and composition. Nature 506, 85-88 (2014).

6. McDowell, N. G. et al. The interdependence of mechanisms underlying climate-driven vegetation mortality. Trends Ecol. Evol. 26, 523-532 (2011).

7. Sterck, F., Markesteijn, L., Schieving, F. \& Poorter, L. Functional traits determine trade-offs and niches in a tropical forest community. Proc. Natl. Acad. Sci. 108, 20627-20632 (2011). 
8. Bell, T., Freckleton, R. P. \& Lewis, O. T. Plant pathogens drive density-dependent seedling mortality in a tropical tree. Ecol. Lett. 9, 569-574 (2006).

9. Janzen, D. H. Herbivores and the number of tree species in tropical forests. Am. Nat. 104, 501-528 (1970).

10. Connell, J. H. Diversity in tropical rain forests and coral reefs. Science. 199, 13021310 (1978).

11. Brienen, R. J. W. et al. Long-term decline of the Amazon carbon sink. Nature 519, $344-348$ (2015).

12. Engelbrecht, B. M. J. et al. Drought sensitivity shapes species distribution patterns in tropical forests. Nature 447, 80-82 (2007).

13. Curran, L. M. et al. Impact of El Niño and logging on canopy tree recruitment in Borneo. Science. 286, 2184-2188 (1999).

14. Doughty, C. E. et al. Allocation trade-offs dominate the response of tropical forest growth to seasonal and interannual drought. Ecology 95, 2192-2201 (2014).

15. Rowland, L. et al. Death from drought in tropical forests is triggered by hydraulics not carbon starvation. Nature 528, 119-122 (2015).

16. Isbell, F. et al. Biodiversity increases the resistance of ecosystem productivity to climate extremes. Nature 526, 574-577 (2015).

17. Morin, X., Fahse, L., de Mazancourt, C., Scherer-Lorenzen, M. \& Bugmann, H. Temporal stability in forest productivity increases with tree diversity due to asynchrony in species dynamics. Ecol. Lett. 17, 1526-1535 (2014).

18. Sakschewski, B. et al. Resilience of Amazon forests emerges from plant trait diversity. Nat. Clim. Chang. 6, 1032-1036 (2016). 
19. Lewis, S. L., Brando, P. M., Phillips, O. L., van der Heijden, G. M. F. \& Nepstad, D. The 2010 Amazon drought. Science. 331, 554 (2011).

20. Laurance, S. et al. Long-term variation in Amazon forest dynamics. J. Veg. Sci. 20, $323-333$ (2009).

21. Levine, J. M. \& HilleRisLambers, J. The importance of niches for the maintenance of species diversity. Nature 461, 254-257 (2009).

22. Darwin, C. On the origins of species by means of natural selection. (Murray, 1859).

23. Ashton, P., Givnish, T. \& Appanah, S. Staggered flowering in the Dipterocarpaceae: new insights into floral induction and the evolution of mast fruiting in the aseasonal tropics. Am. Nat. 132, 44-66 (1988).

24. Gibbons, J. M. \& Newbery, D. M. Drought avoidance and the effect of local topography on trees in the understorey of Bornean lowland rain forest. Plant Ecol. 164, $1-18(2003)$.

25. O’Brien, M. J., Burslem, D. F. R. P., Caduff, A., Tay, J. \& Hector, A. Contrasting nonstructural carbohydrate dynamics of tropical tree seedlings under water deficit and variability. New Phytol. 205, 1083-1094 (2015).

26. Brassard, B. W. et al. Tree species diversity increases fine root productivity through increased soil volume filling. J. Ecol. 101, 210-219 (2013).

27. Wiley, E. \& Helliker, B. A re-evaluation of carbon storage in trees lends greater support for carbon limitation to growth. New Phytol. 195, 285-289 (2012).

28. Körner, C. Paradigm shift in plant growth control. Curr. Opin. Plant Biol. 25, 107-114 (2015).

29. Muller, B. et al. Water deficits uncouple growth from photosynthesis, increase C 
content, and modify the relationships between $\mathrm{C}$ and growth in sink organs. $J$. Exp. Bot. 62, 1715-1729 (2011).

30. O’Brien, M. J., Leuzinger, S., Philipson, C. D., Tay, J. \& Hector, A. Drought survival of tropical tree seedlings enhanced by non-structural carbohydrate levels. Nat. Clim. Chang. 4, 710-714 (2014).

31. Adams, H. et al. A multi-species synthesis of physiological mechanisms in droughtinduced tree mortality. Nat. Ecol. Evol. doi, 10.1038/s41559-017-0248-x (2017).

32. Have, P. et al. Predators have large effects on ecosystem properties by changing plant diversity, not plant biomass. Control 87, 1432-1437 (2006).

33. Güsewell, S. N:P ratios in terrestrial plants: Variation and functional significance. New Phytol. 164, 243-266 (2004).

34. Adler, P. B., HilleRislambers, J. \& Levine, J. M. A niche for neutrality. Ecol. Lett. 10, 95-104 (2007).

35. Sack, L. \& Grubb, P. J. The combined impacts of deep shade and drought on the growth and biomass allocation of shade-tolerant woody seedlings. Oecologia 131, $175-185$ (2002).

36. Nakagawa, M. et al. Impact of severe drought associated with the 1997-1998 El Niño in a tropical forest in Sarawak. J. Trop. Ecol. 16, 355-367 (2000).

37. Newbery, D. M. \& Lingenfelder, M. Resistance of a lowland rain forest to increasing drought intensity in Sabah, Borneo. J. Trop. Ecol. 20, 613-624 (2004).

38. Martinez-Vilalta, J. \& Lloret, F. Drought-induced vegetation shifts in terrestrial ecosystems: The key role of regeneration dynamics. Glob. Planet. Change 144, $94-$ $108(2016)$. 
39. Granados, A., Brobie, J. F., Bernard, H. \& O’Brien, M. J. Defaunation and habitat disturbance interact synergistically to alter seedling recruitment. Ecol. Appl. doi, 10.1002/eap.1592 (2017).

40. Bartlett, M. K. et al. Drought tolerance as a driver of tropical forest assembly: Resolving spatial signatures for multiple processes. Ecology 97, 503-514 (2016).

Supplementary Information is linked to the online version of the paper at

www.nature.com/nature.

\section{Acknowledgements}

This research was supported by the University Research Priority Program on Global Change and Biodiversity at the University of Zurich (URPP-GCB), the Southeast Asian Rainforest Research Partnership (SEARRP) and the NERC Human Modified Tropical Forests programme (BALI project). MOB was funded by a Swiss National Science Foundation Postdoc Mobility Grant (P300PA_167758). Great appreciation goes to our hard-working staff at the Malua Field Station, especially site manager Philip Ulok and Remmy Murus. Thanks to Fauzi Osman and Achung for their tireless work on this experiment and to Lindsay Turnbull and 3 anonymous reviewers for comments on the manuscript. This experiment is SBE manuscript number 19.

Author Contributions: MOB came up with the concept, designed and carried out the experiment, analyzed the data and wrote the manuscript. GR and RO contributed to the logistics and implementation of the experiment in Sabah. AH contributed to the design, analysis and writing.

\section{Author Information}


305 Reprint and permissions information is available at www.nature.com/reprints. The authors

306 declare no competing financial interests. Correspondence and requests for materials should be 307 addressed to: mikey.j.obrien@gmail.com 

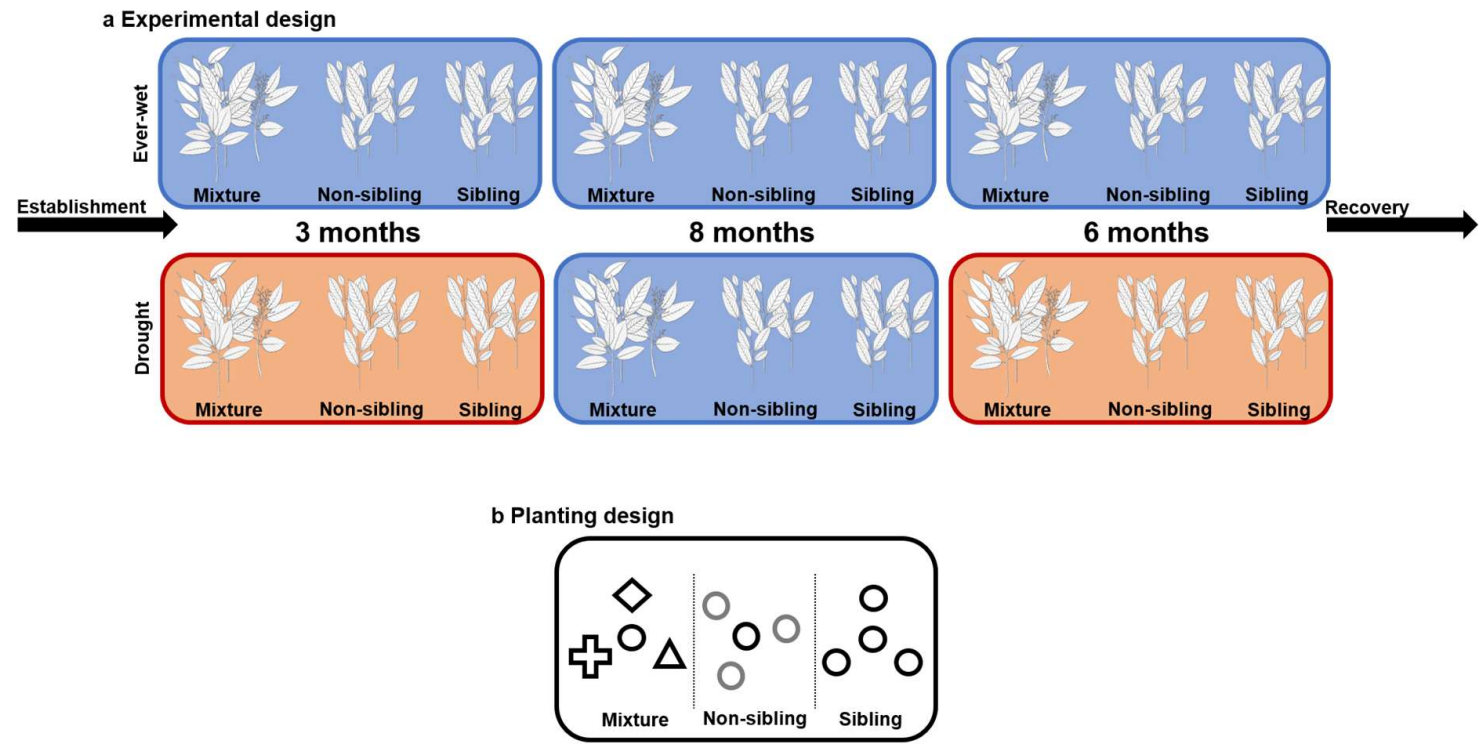

310 Fig. 1 Experimental and planting design. (a) The experimental design consisted of two

311 sub-plots each with a distinct rainfall treatment: ever-wet (blue) and drought (red). (b) Within

312 each rainfall treatment, there were three neighbourhood treatments: 1) mixtures with three

313 different species than the focal seedling, 2) non-sibling monocultures with individuals from a

314 different mature tree than the focal seedling and 3) sibling monocultures with individuals

315 from the same mature tree as the focal seedling. These three conditions were replicated for

316 each of the focal species (Dryobalanops lanceolata, Hopea sangal, Parashorea malaanonan

317 and Shorea parvifolia) under both drought and ever-wet conditions in 20 plots. The mixture

318 neighbourhoods were standardized for all focal species using three additional species (Hopea

319 nervosa, Parashorea tomentella and Shorea argentifolia). 

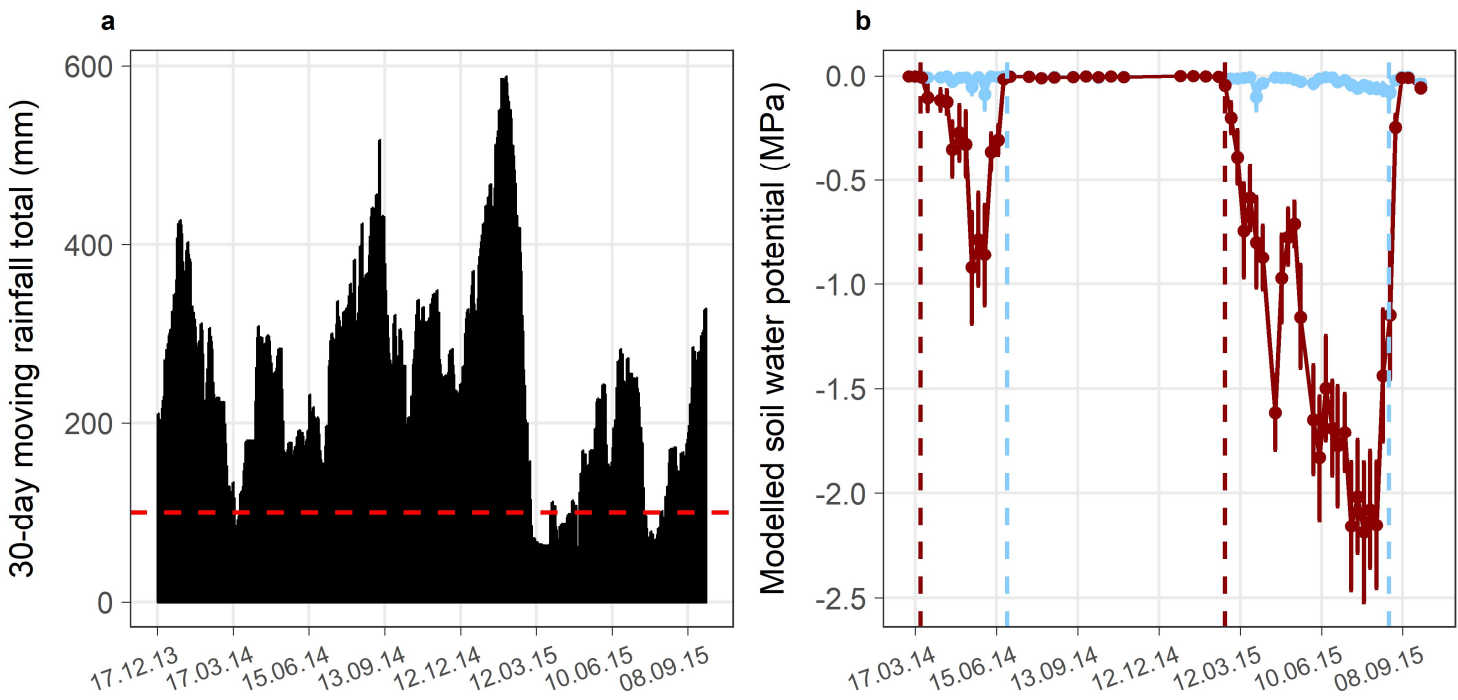

Fig. 2 Rainfall and soil water potential during the 2 years of the experiment. (a) The 30 -

day cumulative rainfall from the first measurement of height. The red dashed line is the

predicted rainfall threshold for drought. (b) Modelled soil water potential (95\% CI) during the

two years of the experiment for drought (red lines and dots) and ever-wet (blue lines and

dots) treatments $(n=20$ for each rainfall treatment per sample after averaging $3-5$

measurements per sub-plot). The vertical dashed lines represent the start (red) and end (blue)

327 of the rainfall-exclusion shelters. The soil moisture was converted from volumetric soil

moisture $(\%)$ to water potential $(\mathrm{MPa})$ using the filter paper method. The soil water potential reached minimums similar to that measured during the El Niño droughts in 1997 and $1998^{24}$. 

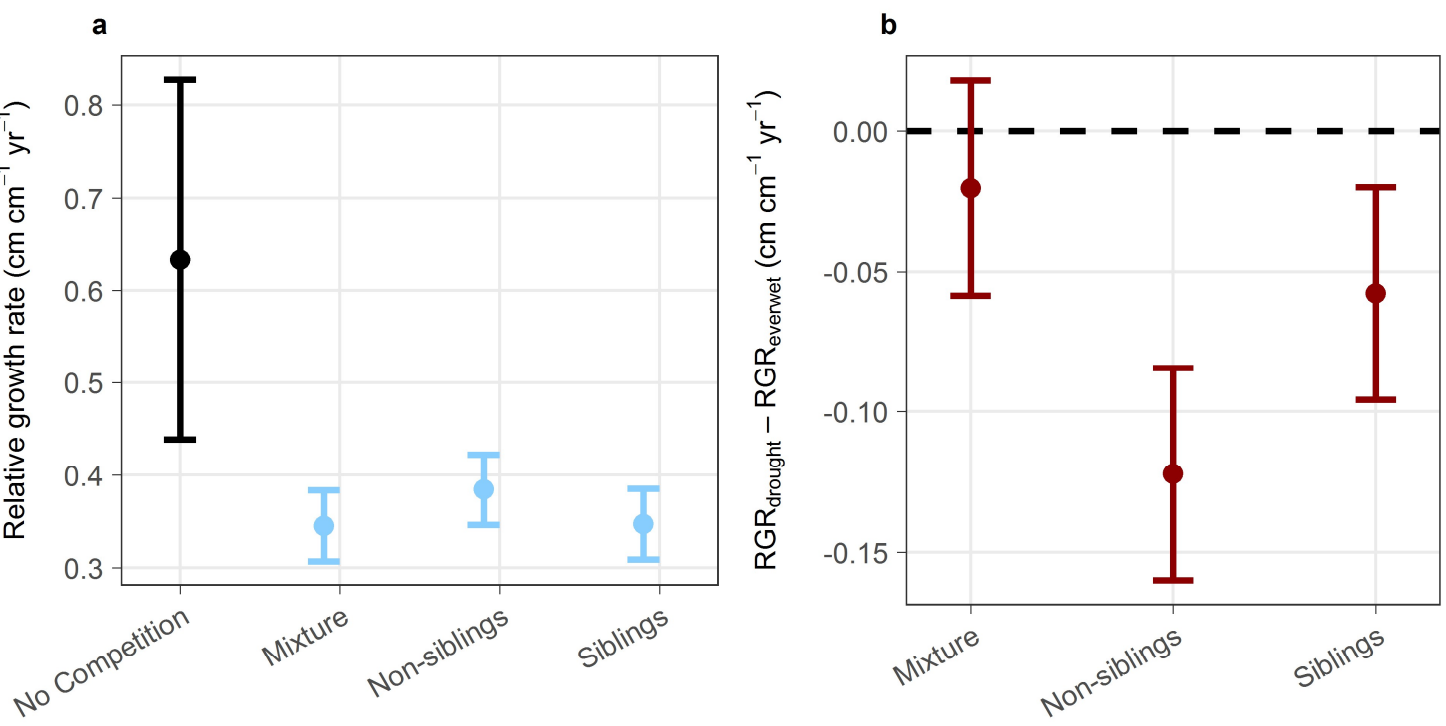

330

331

332

333

334

335

336

337

338

339

340

341

342

343

344

Fig. 3 Relative growth rate for each neighbourhood and water treatment. (a) Relative

growth rate $(95 \% \mathrm{CI})$ for seedlings under ever-wet (blue) conditions for mixture, non-sibling and sibling neighbourhoods $(\mathrm{n}=80$ for each neighbour $\times$ rainfall treatment). The black point is the estimated RGR $(95 \% \mathrm{CI})$ without competition from a similar experiment in the Malua Forest ${ }^{3}$. It represents the maximum growth rate potential for seedlings of these species. (b) Difference in relative growth rate $(95 \% \mathrm{CI})$ was statistically indistinguishable between drought and ever-wet seedlings - i.e. 95\% CI in the difference crosses zero (black dashedline) — with mixture neighbourhoods (reduction in RGR due to drought $=-0.02 \mathrm{~cm} \mathrm{~cm}^{-1} \mathrm{yr}^{-1}$, $-0.06-0.02)$. However, growth was significantly reduced under drought in non-sibling (reduction in RGR due to drought $=-0.12 \mathrm{~cm} \mathrm{~cm}^{-1} \mathrm{yr}^{-1}, 95 \% \mathrm{CI}:-0.16$ to -0.08 ) and sibling (reduction in RGR due to drought $=-0.06 \mathrm{~cm} \mathrm{~cm}^{-1} \mathrm{yr}^{-1},-0.1$ to -0.02 ) neighbourhoods. RGR was calculated at a standardized average height of $50.75 \mathrm{~cm}$ to compare among individuals with initial size differences. A covariate for focal seedling size relative to average neighbour size was used to account for initial height differences among competing individuals. 

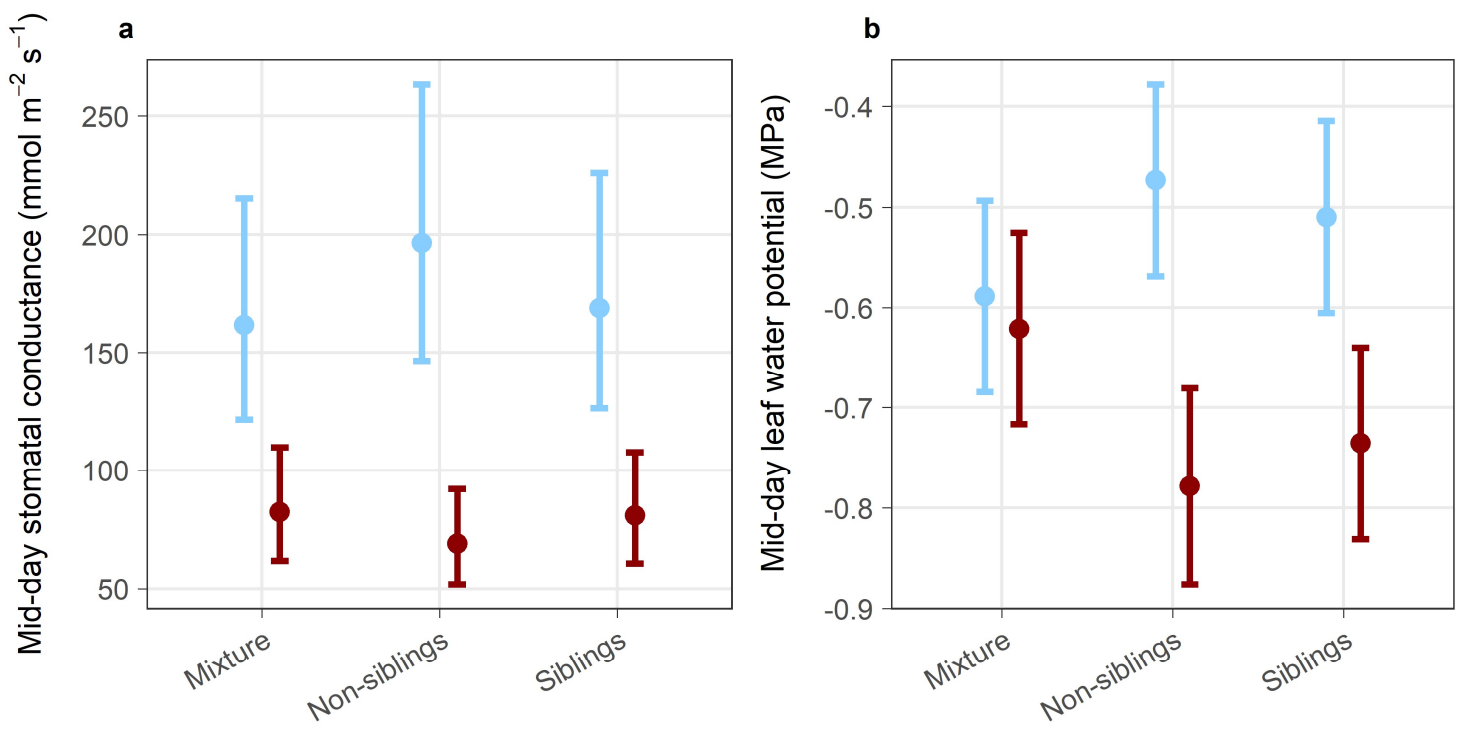

346 Fig. 4 Seedling water stress under rainfall and neighbourhood treatments. Physiological

347 response of seedlings to drought (red) and ever-wet (blue) conditions with mixture, non-

348 sibling and sibling neighbourhoods. (a) Mid-day stomatal conductance in the drought and

349 everwet treatment (95\% CI) was significantly lower in all neighbourhoods $(\mathrm{n}=32$ for each

350 neighbourhood $\times$ rainfall treatment). Stomatal data was log-transformed but is presented on

351 normal-scale after back transformation. (b) Leaf water potentials (95\% CI) were significantly

352 lower under drought for non-sibling and sibling neighbourhoods $(\mathrm{n}=24$ for each

353

neighbourhood $\times$ rainfall treatment), but leaf water potential was statistically

354 indistinguishable between drought and ever-wet conditions in mixtures. 
355

356

357

358

359

360

361

362

363

364

365

366

367

368

369

370

371

372

373

374

375

376

377

378

\section{Methods}

Site description

We established the experiment in Malua Forest nearby to the Malua Field Station (N05'05'20' E117'38'32''; 102 masl). This forest is located $\approx 22 \mathrm{~km}$ north of Danum Valley Field Center in Sabah, Malaysia. Eastern Sabah has historically had an aseasonal climate and for the last 25 years an average monthly rainfall (se) of $240 \mathrm{~mm}$ (33) and an average yearly total of $2900 \mathrm{~mm}$ (90), as recorded at Danum Valley Field Centre. The mean temperature during the experiment was $25.6{ }^{\circ} \mathrm{C}$ with an average daily low of $22.6{ }^{\circ} \mathrm{C}$ and high of $31.5^{\circ} \mathrm{C}$.

\section{Experimental design}

In May 2013, seedlings of four dipterocarp species (Dryobalanops lanceolata, Hopea sangal, Parashorea malaanonan and Shorea parvifolia) were planted into 20 plots randomly distributed across a small topographic gradient from 100 to 130 masl. The species were selected to represent a range of different functional traits and growth/allocation strategies (Supplementary Fig. 4 for trait differences among species). Seeds of the four species were collected in August and September 2010, and seedlings were grown in a standard nursery environment with 5\% sunlight for the two years prior to being planted into the forest. Seeds were collected from three different mature trees for every species except $H$. sangal which only had two mature trees. Each plot consisted of two sub-plots. Within each sub-plot, we planted three focal seedlings of each species (20 plots x 2 sub-plots x 4 species x 3 seedlings $=480$ focal seedlings). For each species within each plot, the focal seedlings originated from the same mature tree, and seedlings from each mature tree were planted as focal seedlings in $8-12$ plots (depending on seedling quantities). Seedlings that died in the first 5 months were replanted (all plants were alive and healthy at the first measurement in December 2013).

\section{Neighbourhood treatments}


of different species (mixture), 2) seedlings of the same species but from a different mature tree (non-sibling) and 3) seedlings of the same species and from the same mature tree

(sibling). To standardize the interspecific competition for all focal species, three dipterocarp species that were not used as focal seedlings (Hopea nervosa, Parashorea tomentella and

Shorea argentifolia) were planted as the neighbourhood. These species were selected because they span a similar spectrum of growth strategies to that of the focal species. The neighbourhoods consisted of three seedlings planted in a triangle pattern at approximately 15 $\mathrm{cm}$ from the focal seedling ( 480 focal seedlings $\mathrm{x} 3$ neighbours $=1440$ neighbourhood of 16 seedling $\mathrm{m}^{-2}$, but concentrated densities around focal seedlings (based on planting distance) could be estimated at 42 seedling $\mathrm{m}^{-2}$. However, these values fall within the natural densities $\left(\right.$ mean $=22$ seedlings $\mathrm{m}^{-2}$ and range $=3-75$ seedlings $\mathrm{m}^{-2}$ ) monitored for 4 years after a mast fruiting event in 81 plots at the Malua Forest Reserve.

\section{Rainfall exclusion treatment}

From 23 March to 27 June 2014 and 23 February to 24 August 2015, rainfallwere made of clear polyethylene sheeting draped over the plots (covering an area of approximately $1.8 \times 2.3 \mathrm{~m}$ ) at a height of approximately 3 meters. The rainfall-exclusion shelters were designed to remove $100 \%$ of rainfall within the sub-plot. Small aluminum barriers (10 $\mathrm{cm}$ high and buried $5 \mathrm{~cm}$ in the soil) were placed upslope from every drought sub-plot to prevent overland flow into the rainfall exclusion shelter during heavy rain events. rain occurred naturally. This watering was also done for both sub-plots when rainfallexclusion shelters were absent in an effort to limit the drought treatment to only the periods 
when rainfall-exclusion shelters were present. Because the shelters prevented leaves and woody debris from falling into the sub-plot, we added surrounding litter on a weekly basis in order to maintain litter levels approximately equal to that of the sub-plot without an exclusion shelter (i.e. a constant layer of litter with no bare soil).

\section{Environmental conditions}

Volumetric soil moisture content was measured weekly at a depth of approximately $10-15 \mathrm{~cm}$ (equivalent to approximately half of the rooting depth of the seedling based on a root growth experiment) during the drought at three to five locations in each sub-plot with an ML3 Theta Probe and HH2 moisture meter (Delta-T Devices, Burwell, Cambridge, UK). The frequency of these measurements was decreased to biweekly when the rainfall-exclusion shelters were removed and monthly during the rainiest period from November to February. The relationship between soil water potential and volumetric soil moisture content was determined using the filter paper method ${ }^{1,2}$. A single batch of Whatman no. 42 filter papers were used in measuring the gravimetric water content in the filter paper that allowed calculation of soil matric potential using the equations from Deka et al. $1995^{1}$. Soils were dried to levels between 2 and 50\% volumetric soil moisture, which were used to calculate a drying curve relating volumetric soil moisture and soil matric potential. Two equations were defined (above and below 25\% volumetric soil moisture) because soil matric potential declined at a faster rate below this threshold.

Photosynthetically active radiation using quantum sensors (Delta-T Devices, Burwell, Cambridge, UK) was measured in each sub-plot for 24 hours and compared to simultaneous measurements of direct sunlight at the Malua Field Station, in order to assess the light differences among plots and between sub-plots within a plot. Light was statistically indistinguishable between sub-plots (difference between sub-plots with and without rainfall- 
428 exclusion shelters $=0.9 \%, 95 \% \mathrm{CI}:-0.8-2.5$ ) and ranged from $1 \%$ to $10 \%$ among plots.

429 Temperature was measured simultaneously with light and was statistically different between

430 sub-plots (difference between sub-plots with and without rainfall-exclusion shelters $=0.2{ }^{\circ} \mathrm{C}$,

$43195 \%$ CI: $0.0-0.4$ ), but this difference is likely biologically unimportant in this climate with

432 persistent high temperatures and humidity.

433

434

Seedling measurements

435

Beginning in December 2013 (after mortality from planting shock had subsided), we

measured all seedlings for height, diameter at base $(1 \mathrm{~cm}$ above the soil) and counted all

437

leaves. Seedling deaths were recorded for both the focal and neighbourhood seedlings. These measurements were done approximately every 80 days between December 2013 and October 2015.

In June 2015 during the second drought period, one mature leaf was removed from every focal seedling weighed wet, photographed to calculate leaf area and then dried at $64{ }^{\circ} \mathrm{C}$ 442 for one week and weighed again. Specific leaf area was calculated from each leaf 443 measurement for each focal seedling. Leaves were selected based on 3 criteria: 1) young but 444 fully developed, 2) in direct sunlight and 3) without herbivory. However, in plots where these 445 criteria could not be met, leaves in similar conditions across the rainfall and neighbourhood 446 treatments were selected to allow comparisons. Furthermore, a subset of 192 focal seedlings 447 from 8 plots were measured for mid-day (between the hours of 11:00 and 13:00) stomatal 448 conductance using a porometer (model SC-1, Decagon Devices, Inc., Pullman, WA, USA) 449 and 120 of those seedlings were also measured for mid-day leaf water potential using a 450 Scholander pressure chamber (model 670, PMS Instrument Co., Corvallis, Oregon, USA). 451 Analysis of the nitrogen and phosphorus content in leaves was done for each species in each 
neighbourhood and each rainfall treatment to test the effect of neighbourhood and drought on nutrient uptake. For this analysis plots were pooled (based on similar light conditions) into 5 groups in order to have enough leaf biomass per sample (4 species x 3 neighbourhoods x 3 rainfall treatments $\mathrm{x} 5$ groups $=120$ nutrient analysis samples).

\section{Statistical analysis}

To estimate relative growth rate for each seedling, height was log transformed and analyzed as a function of time (a continuous variable in years; days since the first measurement divided by 365.25 ) in a mixed-effects model with random intercepts and slopes for individuals (a random factor with 480 levels). These relative growth rate values were then analyzed as a function of species (a fixed factor with four levels; Dryobalanops lanceolata, Hopea sangal, Parashorea malaanonan and Shorea parvifolia), neighbourhood treatment (a fixed factor with three levels; siblings, non-sibling and mixture), rainfall treatment (a fixed factor with two levels; ever-wet and drought), all two-way interactions and a neighbourhood $\times$ rainfall $\times$ species interaction. Covariates for initial seedling height (a continuous variable in $\mathrm{cm}$ ) to account for initial height differences among focal seedlings and relative size (a continuous variable; seedling height relative to average neighbour height) to account for initial differences between focal seedlings and their neighbourhood were used to control for differential size effects. We also used an a priori contrast to test whether mixture and monoculture neighbourhoods accounted for most of the variation in neighbourhood treatments at every interaction level. Random effects were used for plot (a random term with 20 levels), sub-plot nested in plot (a random term with 40 levels), species nested in sub-plot nested in plot (a random term with 160 levels) and neighbourhood treatment nested in subplot nested in plot (a random term with 120 levels). See Supplementary Table 1 for the ANOVA table and variance components. We also performed this analysis separately for each 
476 year of the drought to validate that the results were consistent across years and not solely a 477 cumulative effect (Supplementary Fig. 5 for this validation).

Mid-day leaf water potential and stomatal conductance were analyzed as a function of species (a fixed factor with four levels; Dryobalanops lanceolata, Hopea sangal, Parashorea malaanonan and Shorea parvifolia), neighbourhood treatment (a fixed factor with three levels; siblings, non-sibling and mixture), rainfall treatment (a fixed factor with two levels; ever-wet and drought) and the interaction between neighbourhood and rainfall treatments. Random effects were used for plot (a random term with 20 levels), sub-plot nested in plot (a random term with 40 levels), species nested in plot (a random term with 80 levels) and neighbourhood treatment nested in sub-plot nested in plot (a random term with 120 levels). The stomatal conductance data were log-transformed to meet assumptions of linearity. leaf water potential but with a modified random error structure because plots were pooled.

489 Random effects were used for group (a random term with 5 levels), sub-plot nested in group 490 (a random term with 10 levels), species nested in group (a random term with 20 levels), neighbourhood nested in group (a random term with 15 levels), neighbourhood treatment nested in sub-plot nested in plot (a random term with 30 levels). All analyses were performed with the asreml-R package (ASReml 3, VSN International, UK) in the R statistical software

494 (version 3.3.2; http://r-project.org).

\section{Data availability}

496 The data that support the findings of this study are available from the corresponding author 497 upon reasonable request and will be publicly available on www.searrp.org. 
499 All R script will be made available in the Supplementary Information.

\section{Method references}

501 1. Deka, R. et al. Use and accuracy of the filter-paper technique for measurement of soil

502 matric potential. Eur. J. Soil Sci. 46, 233-238 (1995).

503 2. O’Brien, M. J., Philipson, C. D., Tay, J. \& Hector, A. The influence of variable rainfall 504 frequency on germination and early growth of shade-tolerant dipterocarp seedlings in

$505 \quad$ Borneo. PLoS One 8, e70287 (2013). 


\section{Supplementary Information}

\section{Supplementary Table 1. RGR ANOVA.}

Supplementary Table 2. ANOVA of leaf water potential and stomatal conductance. Supplementary Table 3. ANOVA of leaf nutrients.

Supplementary Fig. 1. Stomatal changes with drought.

Supplementary Fig. 2. Leaf nutrients.

Supplementary Fig. 3. Species level growth differences.

Supplementary Fig. 4 Functional trait differences among species.

Supplementary Fig. 5 Growth response for each year of the experiment.

Supplementary Fig. 6 Revised Figure 2 presenting plot level differences.

R Code Growth.

R Code Leaf Physiology.

R Code Nutrients.

Resistance of tropical seedlings to drought is mediated by neighbourhood diversity

Michael J. O’Brien ${ }^{1,2}$, Glen Reynolds ${ }^{2}$, Robert Ong ${ }^{3}$ and Andy Hector ${ }^{4}$

${ }^{1}$ Estación Experimental de Zonas Áridas, Consejo Superior de Investigaciones Científicas,

Carretera de Sacramento s/n, E-04120 La Cañada, Almería, Spain

${ }^{2}$ Southeast Asia Rainforest Research Partnership, Danum Valley Field Centre, PO Box

60282, 91112 Lahad Datu, Sabah, Malaysia

${ }^{3}$ Forest Research Centre, Sepilok, 90715 Sandakan, Sabah, Malaysia

${ }^{4}$ Department of Plant Sciences, University of Oxford, OXI 3RB UK

*Correspondence author e-mail: mikey.j.obrien@gmail.com 
Supplementary Table 1. The ANOVA table (above) and variance components (below) from the linear mixed-effects model of seedling relative growth rate.

\begin{tabular}{cccc}
\hline Source of variation & d.f. & $\begin{array}{c}\text { denominator } \\
\text { d.f. }\end{array}$ & F \\
\hline Initial height & 1 & 329.9 & $867.9^{* * *}$ \\
Size relative to neighbour & 1 & 390.8 & $3.21^{\dagger}$ \\
Light & 1 & 36.7 & $11.61^{* *}$ \\
Species & 3 & 62 & $8.94^{* * *}$ \\
Mix-mono contrast & 1 & 81.6 & 0.56 \\
Neighbour treatment & 1 & 76.7 & 0.04 \\
Rainfall treatment & 1 & 18.2 & $3.96^{\dagger}$ \\
Species x contrast & 3 & 236.1 & $2.68^{*}$ \\
Species x neighbour & 3 & 227.2 & 0.43 \\
Species x rainfall & 3 & 56.9 & 0.63 \\
Contrast x rainfall & 1 & 76.3 & $4.43^{*}$ \\
Neighbour x rainfall & 1 & 75.6 & $2.91^{\dagger}$ \\
Species x contrast x rainfall & 3 & 226.1 & $3.73^{*}$ \\
Species x neighbour x rainfall & 3 & 225.9 & 1.33 \\
\hline Variance components & Var. & SE & \\
\hline Plot & 0.016 & 0.007 & \\
Sub-plot:plot & 0.005 & 0.003 & \\
Species:plot & 0.008 & 0.002 & \\
Neighbour:sub-plot:plot & 0.000 & 0.001 & \\
Species:sub-plot:plot & -0.001 & 0.002 & \\
Residual variance & 0.028 & 0.003 &
\end{tabular}

d.f.: degrees of freedom (note effective df can be fractional); F: conditional F-statistic; Var.: variance component estimate; $\mathrm{SE}$ : standard errors of variance component; ${ }^{\dagger} \mathrm{P}<0.1,{ }^{*} \mathrm{P}<0.05$, $* * \mathrm{P}<0.01, * * * \mathrm{P}<0.001$ 
Supplementary Table 2. The ANOVA table from the linear mixed-effects model of (a) leaf water potential and (b) stomatal conductance (presented as in Supplementary Table 1).

\begin{tabular}{|c|c|c|c|}
\hline Source of variation & d.f. & $\begin{array}{c}\text { denominator } \\
\text { d.f. }\end{array}$ & $\mathbf{F}$ \\
\hline \multicolumn{4}{|c|}{ 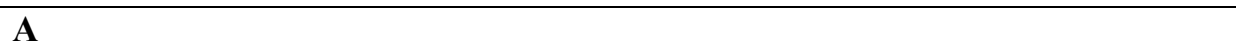 } \\
\hline Species & 3 & 14.9 & $10.8^{* * *}$ \\
\hline Neighbour treatment & 2 & 20.1 & 0.2 \\
\hline Rainfall treatment & 1 & 5 & $32.9 * *$ \\
\hline Neighbour x rainfall & 2 & 20.1 & $8.1 * *$ \\
\hline Variance components & Var. & SE & \\
\hline Plot & 0.006 & 0.005 & \\
\hline Sub-plot:plot & 0.001 & 0.002 & \\
\hline Species:plot & 0.001 & 0.004 & \\
\hline Neighbour:sub-plot:plot & -0.008 & 0.003 & \\
\hline Residual variance & 0.061 & 0.009 & \\
\hline \multicolumn{4}{|l|}{ 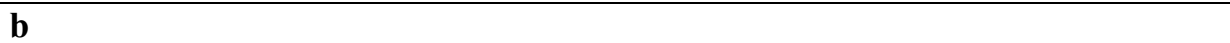 } \\
\hline Species & 3 & 21.1 & $3.1^{\dagger}$ \\
\hline Neighbour treatment & 2 & 28.2 & 0.0 \\
\hline Rainfall treatment & 1 & 7 & $32.5^{* * *}$ \\
\hline Neighbour x rainfall & 2 & 28.3 & 1.4 \\
\hline Variance components & Var. & SE & \\
\hline Plot & -0.01 & 0.04 & \\
\hline Sub-plot:plot & 0.05 & 0.04 & \\
\hline Species:plot & 0.11 & 0.05 & \\
\hline Neighbour:sub-plot:plot & 0.04 & 0.03 & \\
\hline Residual variance & 0.26 & 0.03 & \\
\hline
\end{tabular}

d.f.: degrees of freedom (note effective df can be fractional); F: conditional F-statistic; Var.: variance component estimate; SE: standard errors of variance component; ${ }^{\dagger} \mathrm{P}<0.1,{ }^{*} \mathrm{P}<0.05$, $* * \mathrm{P}<0.01, * * * \mathrm{P}<0.001$ 
Supplementary Table 3. The ANOVA table from the linear mixed-effects model of (a) leaf nitrogen, (b) phosphorus and (c) nitrogen to phosphorus ratio.

\begin{tabular}{|c|c|c|c|}
\hline Source of variation & d.f. & $\begin{array}{c}\text { denominator } \\
\text { d.f. }\end{array}$ & $\mathbf{F}$ \\
\hline \multicolumn{4}{|c|}{ 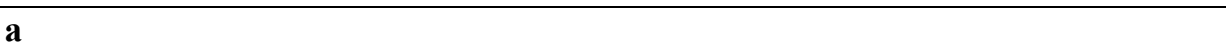 } \\
\hline Species & 3 & 12 & $14.2^{* * *}$ \\
\hline Neighbour treatment & 2 & 5.1 & $6.7^{*}$ \\
\hline Rainfall treamtent & 1 & 4 & 0.5 \\
\hline Neighbour $\mathrm{x}$ rainfall & 2 & 7.6 & 0.3 \\
\hline Variance components & Var. & SE & \\
\hline Group & 0.001 & 0.001 & \\
\hline Sub-plot:group & 0.000 & 0.001 & \\
\hline Neighbour:group & -0.001 & 0.001 & \\
\hline Species:group & 0.002 & 0.001 & \\
\hline Neighbour:sub-plot:group & 0.001 & 0.001 & \\
\hline Mixture variance & 0.007 & 0.002 & \\
\hline Sibling variance & 0.006 & 0.001 & \\
\hline Non-sibling variance & 0.005 & 0.001 & \\
\hline \multicolumn{4}{|l|}{ 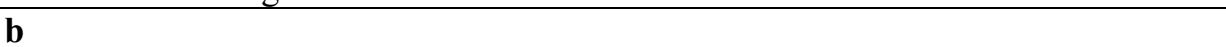 } \\
\hline Species & 3 & 12 & $10.2^{* *}$ \\
\hline Neighbour treatment & 2 & 8.3 & 0.1 \\
\hline Rainfall treamtent & 1 & 3.9 & 4.3 \\
\hline Neighbour x rainfall & 2 & 8.6 & 1.0 \\
\hline Variance components & Var. & SE & \\
\hline Group & 0.007 & 0.006 & \\
\hline Sub-plot:group & -0.001 & 0.001 & \\
\hline Neighbour:group & -0.002 & 0.002 & \\
\hline Species:group & 0.003 & 0.002 & \\
\hline Neighbour:sub-plot:group & 0.004 & 0.003 & \\
\hline Mixture variance & 0.009 & 0.003 & \\
\hline Sibling variance & 0.017 & 0.004 & \\
\hline Non-sibling variance & 0.014 & 0.004 & \\
\hline \multicolumn{4}{|l|}{$x_{0}=0$} \\
\hline Species & 3 & 12 & $57.61 * * *$ \\
\hline Neighbour treatment & 2 & 19.4 & 1.18 \\
\hline Rainfall treamtent & 1 & 19.2 & 2 \\
\hline Neighbour $\mathrm{x}$ rainfall & 2 & 17.8 & 0.31 \\
\hline Variance components & Var. & SE & \\
\hline Group & 0.59 & 0.53 & \\
\hline Sub-plot:group & 0.00 & NA & \\
\hline Neighbour:group & 0.02 & NA & \\
\hline Species:group & -0.04 & 0.24 & \\
\hline Neighbour:sub-plot:group & 0.09 & 0.34 & \\
\hline Mixture variance & 3.21 & 0.84 & \\
\hline Sibling variance & 3.52 & 0.94 & \\
\hline Non-sibling variance & 3.81 & 0.95 & \\
\hline
\end{tabular}

d.f.: degrees of freedom (note effective df can be fractional); F: conditional F-statistic; Var.: variance component estimate; SE: standard errors of variance component; ${ }^{\dagger} \mathrm{P}<0.1, * \mathrm{P}<0.05,{ }^{* *} \mathrm{P}<0.01,{ }^{* * *} \mathrm{P}$ $<0.001$ 


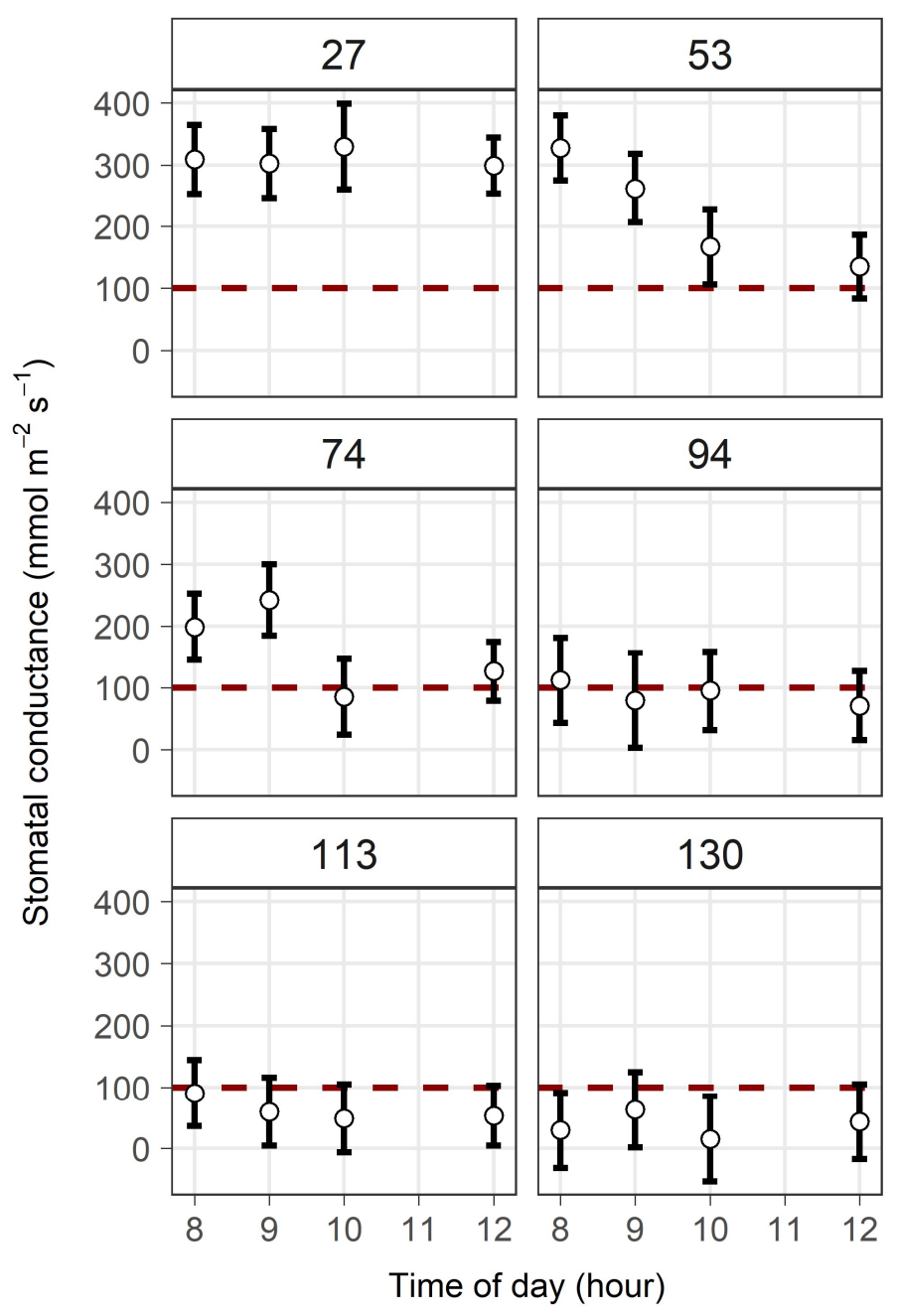

\section{Supplementary Fig. 1 Stomatal conductance from a dry-down pot experiment using}

these species. Each panel is the stomatal conductance $(95 \% \mathrm{CI})$ from 7:00 in the morning to 13:00 in the afternoon through the course of the dry-down. The panels are the mean days since the start of no watering, and the red line is at $100 \mathrm{mmol} \mathrm{m}^{-2} \mathrm{~s}^{-1}$, which is about the threshold the seedlings under rainfall exclusion shelters reached in our experiment. By approximately 90 days, little fluctuation in stomatal conductance occurred during the course of the day. These species only fully close their stomata in severely dry soils and even at that point stomatal leakage continues to occur. 

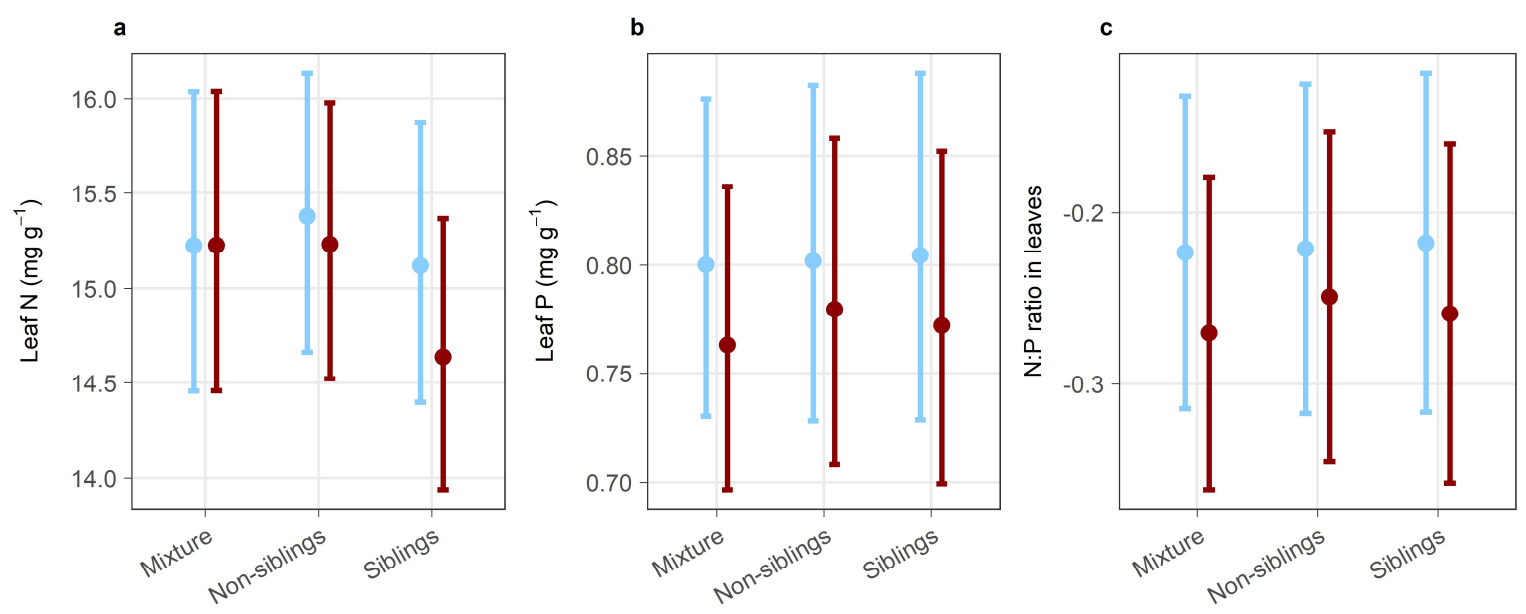

Supplementary Fig. 2 Leaf nutrient concentrations. (a) Leaf nitrogen concentration (95\%

CI) was similar in all treatments. (b) Leaf phosphorus concentration $(95 \% \mathrm{CI})$ was

significantly indistinguishable among all treatment combinations. (c) N:P ratio in the leaves (95\% CI) was significantly indistinguishable among all treatment combinations 

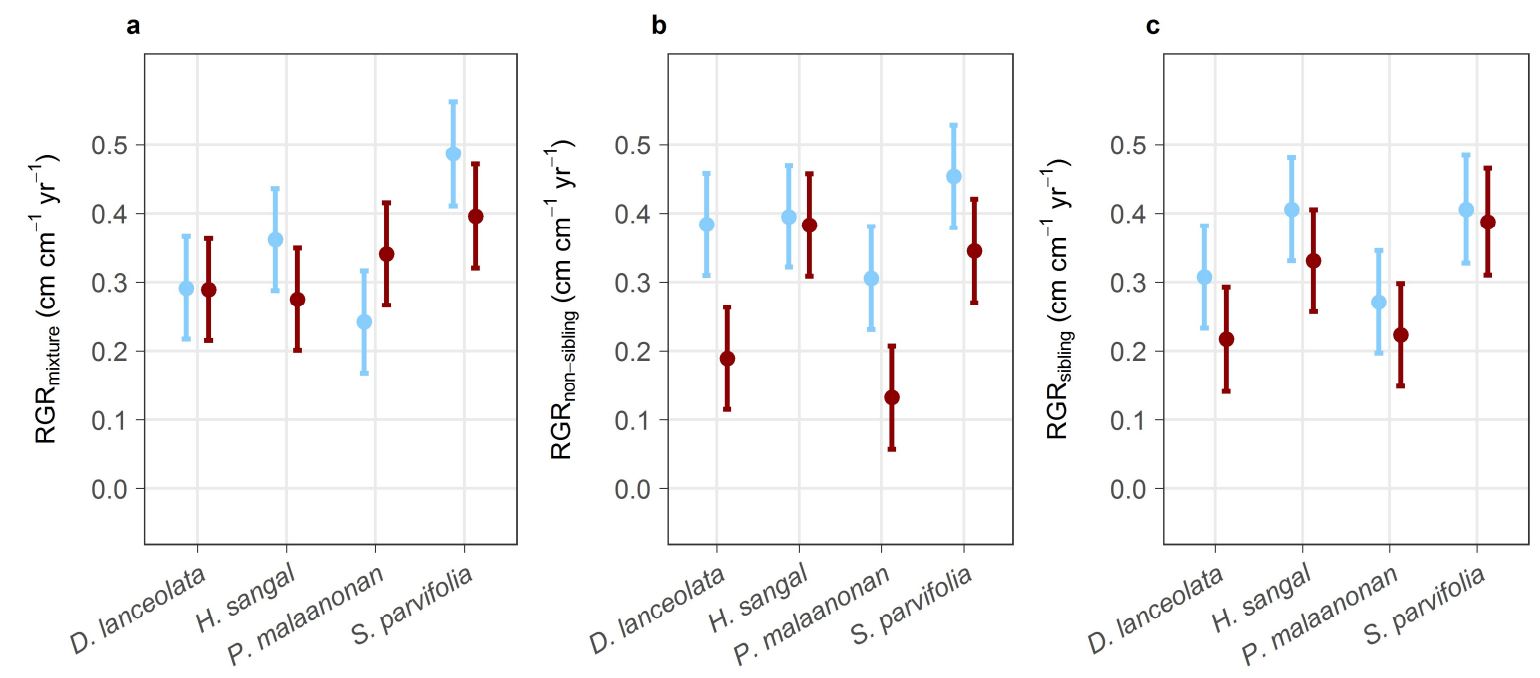

Supplementary Fig. 3 Relative growth rate (RGR) of each species. (a) Three of the four species had lower a relative growth rate $(95 \% \mathrm{CI})$ under drought than everwet in the mixture treatment. In (b) non-sibling and (c) sibling neighbourhoods all species had lower RGR in drought relative to everwet treatments. However, the magnitude of the effect depended on the species and neighbourhood (see significant species $\times$ contrast $\times$ rainfall interaction in Supplementary Table 1). 

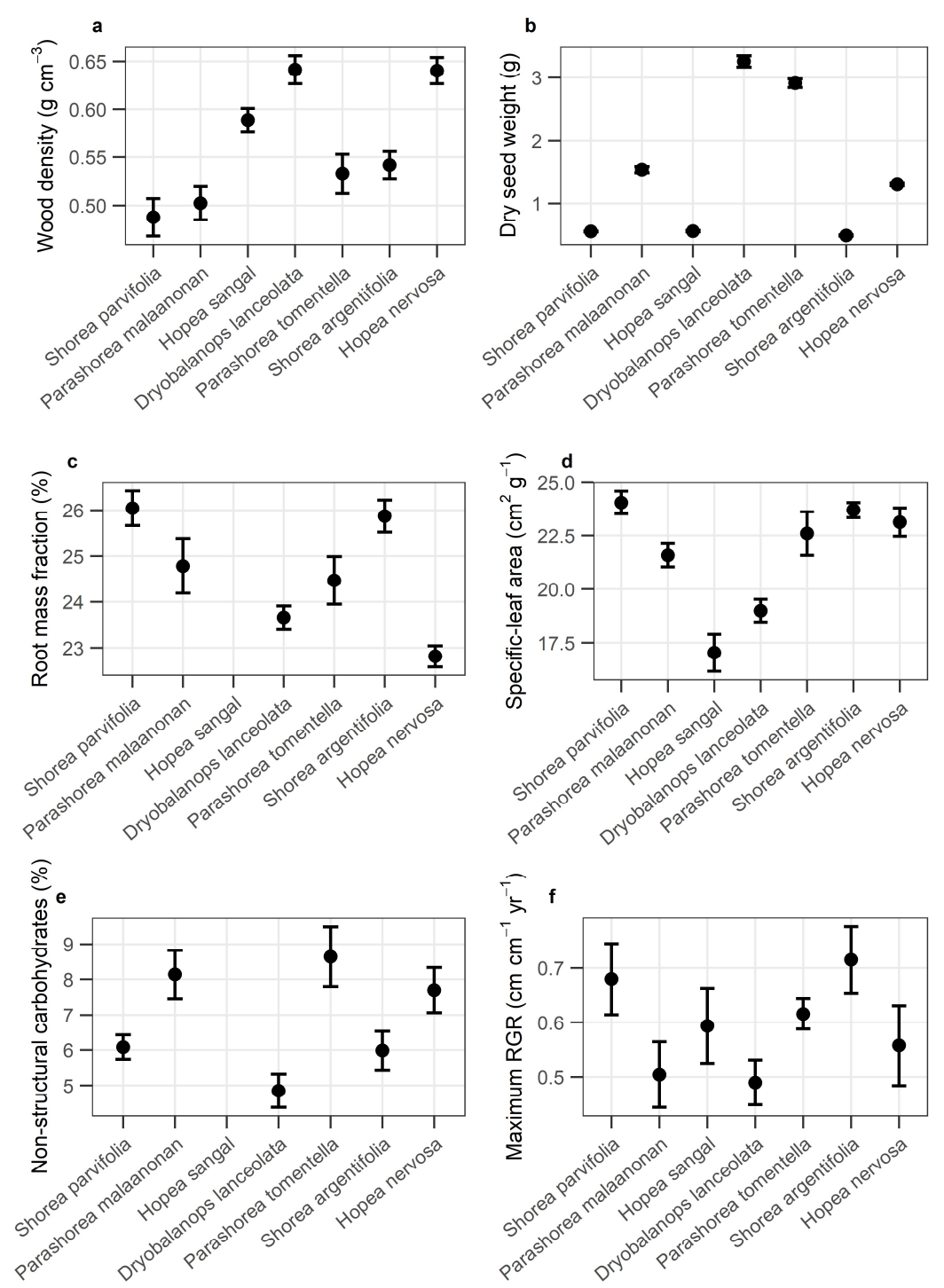

Supplementary Fig. 4 Functional trait differences among species. The mean (s.e.) for six functional traits of seven species used in the experiment. The first four species (from left to right) were focal species (Shorea parvifolia, Parashorea malaanonan, Hopea sangal and Dryobalanops lanceolata) and the last three were used as neighbors in the mixture neighbourhoods (Parashorea tomentella, Shorea argentifolia and Hopea nervosa). The data compiled for these trait estimates were collected from seedlings of previous experiments at the Malua Field Station ${ }^{1-6}$. 

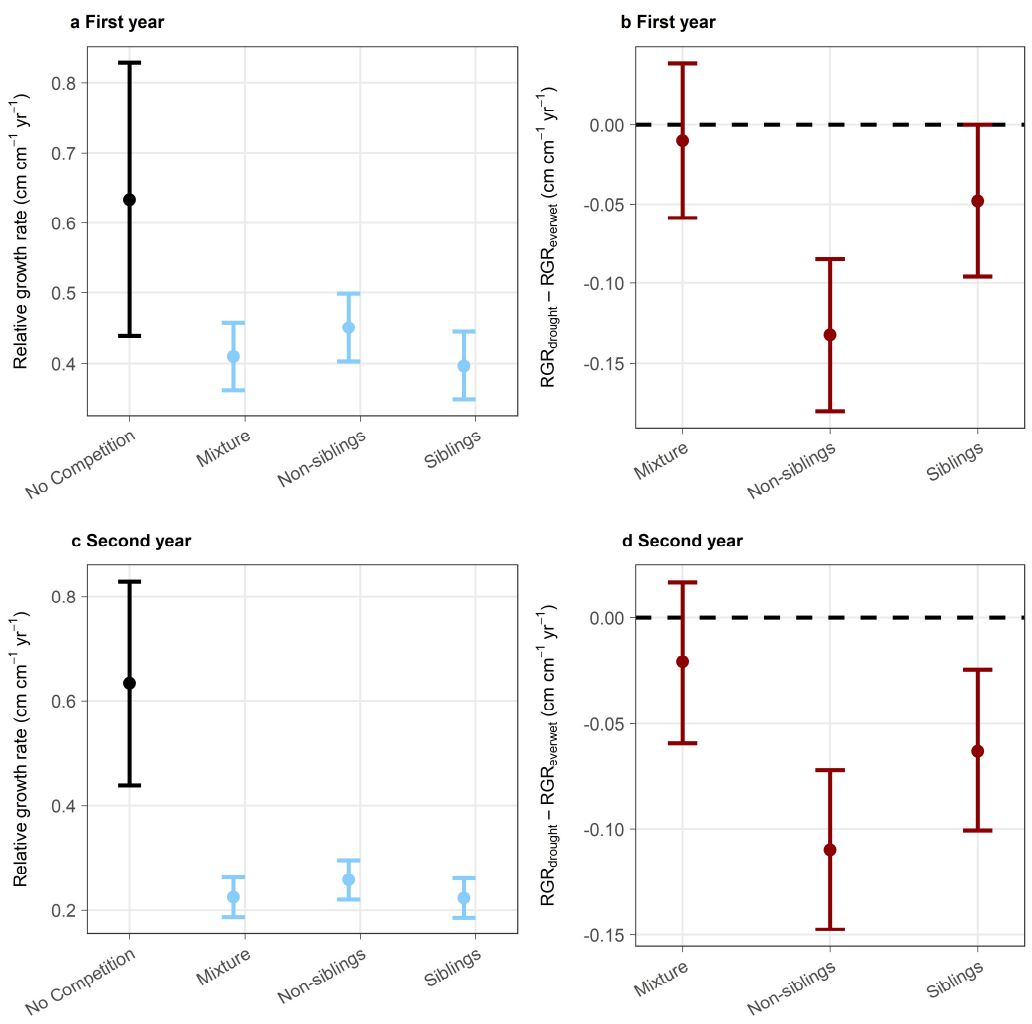

Supplementary Fig. 5 Separate growth response for each year of the experiment. (a and

c) Relative growth rate ( $95 \% \mathrm{CI})$ for seedlings under ever-wet (blue) conditions for mixture, non-sibling and sibling neighbourhoods. The black point is the estimated RGR (95\% CI) without competition from a similar experiment in the Malua Forest ${ }^{3}$. It represents the maximum growth rate potential for seedlings of these species. (b and d) Difference in relative growth rate $(95 \% \mathrm{CI})$ was statistically indistinguishable between drought and ever-wet seedlings with mixture neighbourhoods. However, growth was significantly reduced under drought in non-sibling and sibling neighbourhoods. The effect of drought and competition was stronger in the second year. 

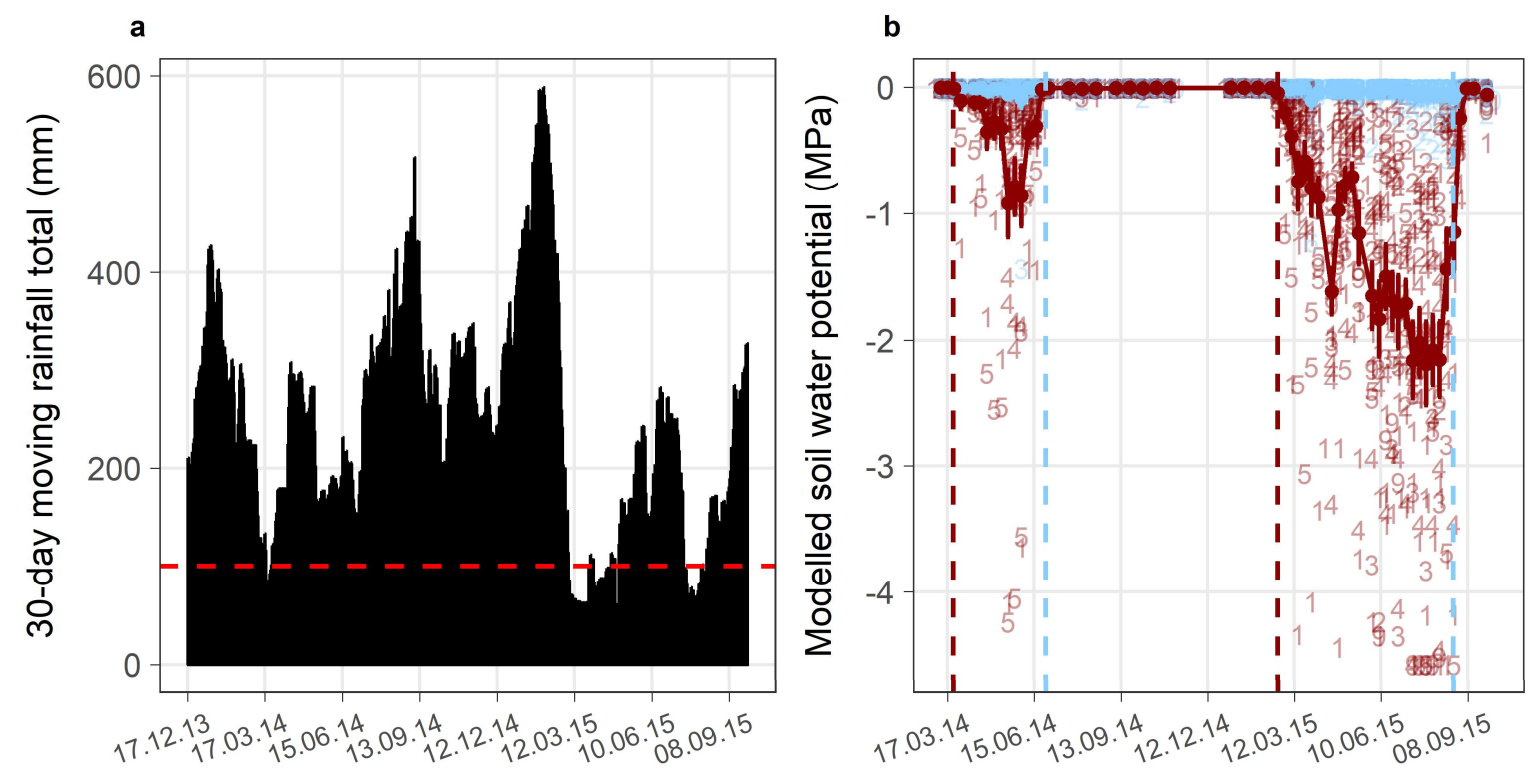

\section{Supplementary Fig. 6 Rainfall and soil water potential during the 2 years of the}

experiment. (a) The 30-day cumulative rainfall from the first measurement of height. The red dashed line is the predicted rainfall threshold for drought. (b) Modelled soil water potential $(95 \% \mathrm{CI})$ during the two years of the experiment for drought (red lines and dots) and ever-wet (blue lines and dots) treatments. The vertical dashed lines represent the start (red) and end (blue) of the rainfall-exclusion shelters. The soil moisture was converted from volumetric soil moisture (\%) to water potential (MPa) using the filter paper method. The numbers represent the measured percentage of direct sunlight in that subplot (i.e. a 1 equals $1 \%$ light or 9 equals $9 \%$ light). 


\section{References}

1. O’Brien, M. J., Leuzinger, S., Philipson, C. D., Tay, J. \& Hector, A. Drought survival of tropical tree seedlings enhanced by non-structural carbohydrate levels. Nat. Clim.

Chang. 4, 710-714 (2014).

2. O’Brien, M. J., Burslem, D. F. R. P., Caduff, A., Tay, J. \& Hector, A. Contrasting nonstructural carbohydrate dynamics of tropical tree seedlings under water deficit and variability. New Phytol. 205, 1083-1094 (2015).

3. O’Brien, M. J., Ong, R. \& Reynolds, G. Intra-annual plasticity of growth mediates drought resilience over multiple years in tropical seedling communities. Glob. Chang. Biol. doi, 10.1111/gcb.13658 (2017).

4. O’Brien, M. J., Philipson, C. D., Tay, J. \& Hector, A. The influence of variable rainfall frequency on germination and early growth of shade-tolerant dipterocarp seedlings in Borneo. PLoS One 8, e70287 (2013).

5. Philipson, C. D. et al. Light-based regeneration niches: Evidence from 21 dipterocarp species using size-specific RGRs. Biotropica 44, 627-636 (2012).

6. Saner, P. et al. Growth rates and relative change in non-structural carbohydrates of dipterocarp seedlings in response to light acclimation. Plant Ecol. Divers. 9, 491-504 (2016). 


\section{R Code Growth}

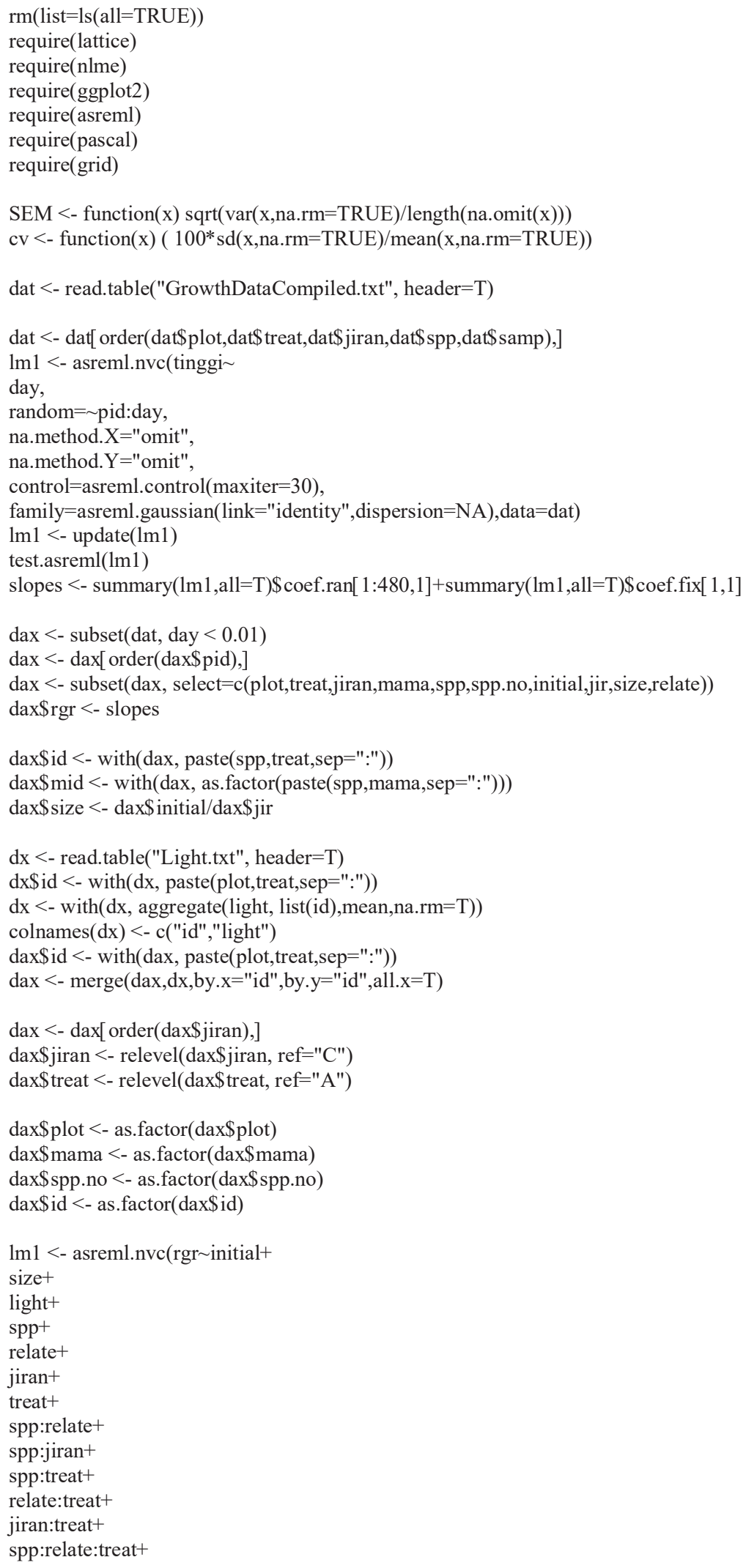


spp:jiran:treat,

random $=\sim$ plot +

plot:treat +

plot:spp+

plot:treat:spp+

plot:treat:jiran,

na.method. $X=$ "omit",

na.method. $Y=$ "omit",

control $=$ asreml. $\operatorname{control}($ maxiter $=30)$,

keep.order $=\mathrm{T}$,

family=asreml.gaussian $($ link="identity",dispersion=NA),data=dax $)$

$\operatorname{lm} 1<-$ update $(\operatorname{lm} 1)$

test.asreml $(\operatorname{lm} 1)$

summary $(\operatorname{lm} 1$, all $=T) \$$ coef.fix

nd $1<-$ predict $(1 \mathrm{~m} 1$,classify = "jiran:treat:initial:relate",

average=c("spp","size","light","plot"),levels=list(initial=50.75))\$predictions\$pvals

nd1 $<$ - subset(nd1, is.na(predicted.value) $==\mathrm{F}$ )

nd $<$ - data.frame $($ jiran $=$ nd $1 \$$ jiran,treat=nd 1 \$treat $)$

nd\$rgr $<-$ with(nd1, predicted.value)

nd $\$$ Up $<-$ with(nd1, predicted.value $+1.96 *$ standard.error)

nd\$Low $<-$ with(nd1, predicted.value - 1.96* standard.error)

nd $<-$ nd[ order(nd\$jiran), $]$

$\mathrm{dt}<-$ dax $[,-1]$

dt\$pnt $<-0.9$

$\mathrm{dt}[$ which(dt\$jiran $==$ "C" \& dt\$treat=="B"),14]<- 1.1

$\mathrm{dt}[$ which(dtSiran $==$ "S" \& dt\$treat=="B"),14]<- 2.1

$\mathrm{dt}[$ which $(\mathrm{dt}$ \$jiran $==$ "M" \& dt\$treat=="B"),14]<- 3.1

$\mathrm{dt}[$ which(dt jiran $==$ "S" \& dt\$treat=="A"),14]<- 1.9

$\mathrm{dt}[$ which(dt\$jiran == "M" \& dt\$treat=="A"),14]<- 2.9

dt\$jiran $<-$ as.factor(dt\$jiran)

$\mathrm{dt} \$$ treat $<$ - as.character $(\mathrm{dt} \$$ treat $)$

$\mathrm{dt}[$ which $(\mathrm{dt}$ \$treat $==$ "A"),2]<- "Everwet"

$\mathrm{dt}[$ which(dt\$treat $==$ "B"),2] <- "Drought"

$\mathrm{dt} \$$ treat $<-$ as.factor $(\mathrm{dt} \$$ treat $)$

nd $\$$ treat $<$ - as.character(nd $\$$ treat)

$\mathrm{nd}[$ which(nd\$treat $==$ "A"),2] <- "Everwet"

nd[ which(nd\$treat $==$ "B"),2]<- "Drought"

nd $\$$ treat $<$ - as.factor(nd\$treat)

$\mathrm{dt} \$$ jiran $<-$ as.character $(\mathrm{dt} \$$ jiran $)$

$\mathrm{dt}[$ which $(\mathrm{dt}$ jiran == "M"),3] <- "Siblings"

$\mathrm{dt}[$ which(dt\$jiran == "S"),3]<- "Intraspecific"

$\mathrm{dt}[$ which $(\mathrm{dt}$ jiran $==$ "C"),3] <- "Interspecific"

dt\$jiran $<-$ as.factor(dt\$jiran)

nd $\$$ jiran $<-$ as.character(nd\$jiran)

nd[ which(nd\$jiran == "M"),1] <- "Siblings"

nd[ which(nd\$iran == "S"),1] <- "Intraspecific"

$\mathrm{nd}[$ which(nd\$jiran == "C"),1] <- "Interspecific"

nd $\$$ jiran $<-$ as.factor(nd $\$$ jiran)

nd\$pnt $<-\mathrm{c}(0.9,1.1,2.9,3.1,1.9,2.1)$

\#\#\#No competition RGR

nd7 <- data.frame(jiran=as.factor("Interspecific"), treat=as.factor("Everwet"),rgr=as.numeric(0.6332351),

$\mathrm{Up}=$ as.numeric $(0.6332351+2 * 0.09744224), \mathrm{Low}=\operatorname{as}$. numeric $(0.6332351-2 * 0.09744224), \mathrm{pnt}=\mathrm{as}$. numeric $(0))$

nd7[1,1]<- "Interspecific"

nd7[1,2]<- "Everwet"

1-(mean(nd\$rgr[1],nd\$rgr[3],nd\$rgr[5])/nd7\$rgr)

$1-(\operatorname{mean}(\mathrm{nd} \$ \mathrm{rgr}[2], \mathrm{nd} \mathbf{\mathrm { rgr }}[4], \mathrm{nd} \$ \mathrm{rgr}[6]) / \mathrm{nd} 7 \mathrm{rgr})$ 


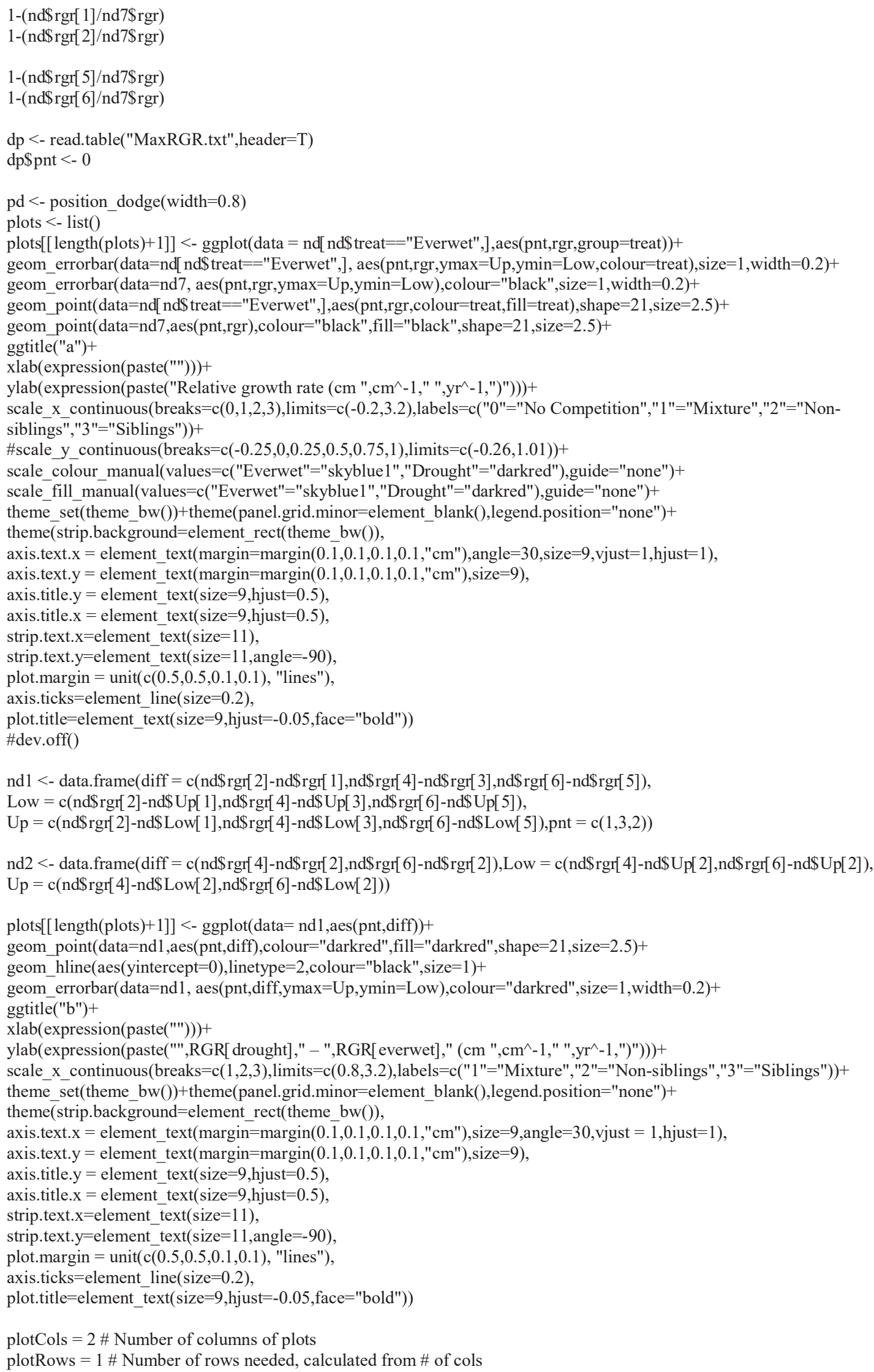




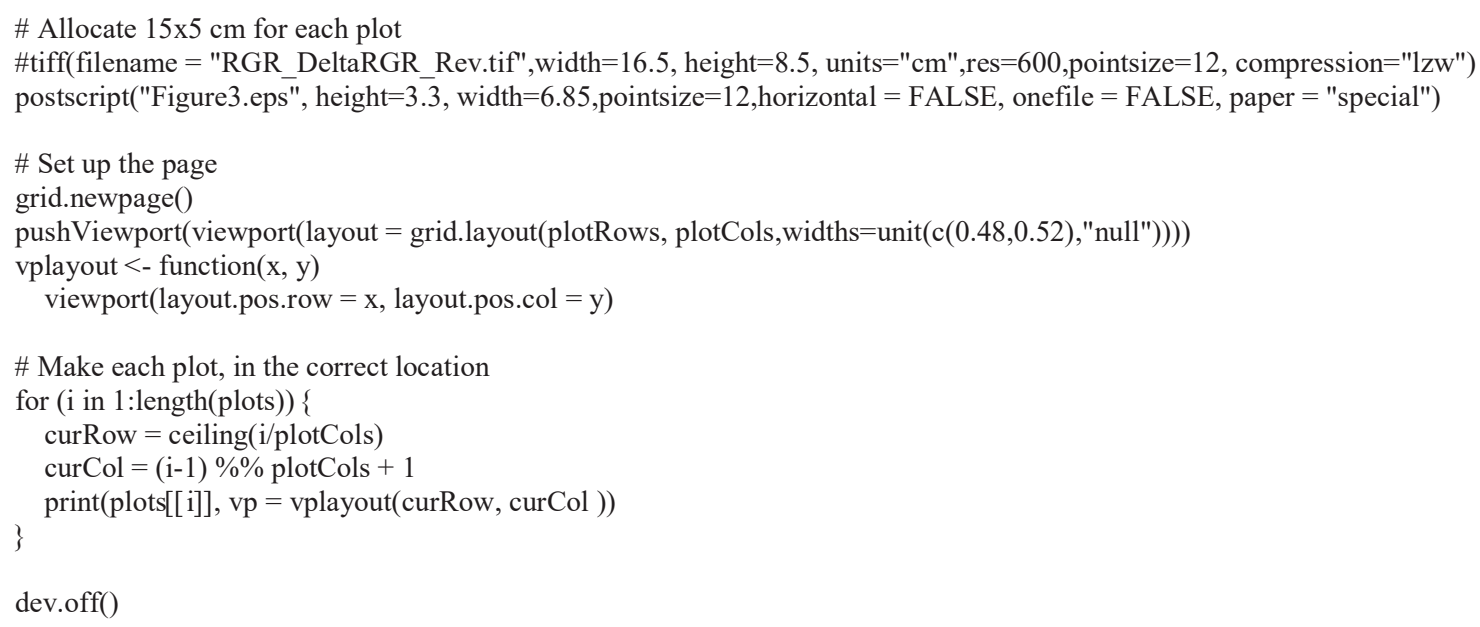

dev.off() 


\section{R Code Leaf Physiology}

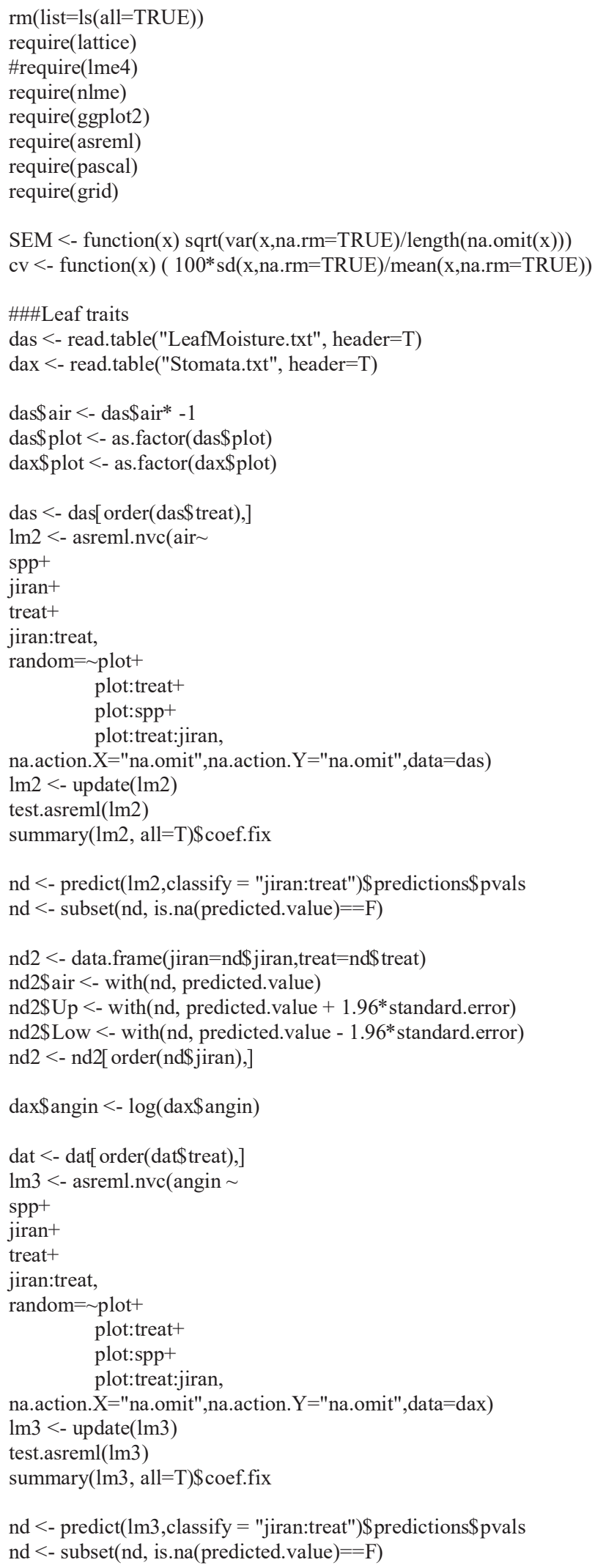


nd3 $<$ - data.frame(jiran=nd\$jiran,treat=nd\$treat $)$

nd3\$ angin $<-$ with(nd, predicted.value)

nd $3 \$$ Up $<-$ with(nd, predicted.value $+1.96 *$ standard.error)

nd3\$Low $<-$ with(nd, predicted.value - 1.96* standard.error)

nd3 <- nd3[ order(nd\$jiran), ]

nd3\$ angin $<-\exp ($ nd3\$ angin $)$

nd3\$Up $<-\exp (n d 3 \$ U p)$

nd3\$Low $<-\exp ($ nd $3 \$$ Low $)$ 


\section{R Code Nutrients}

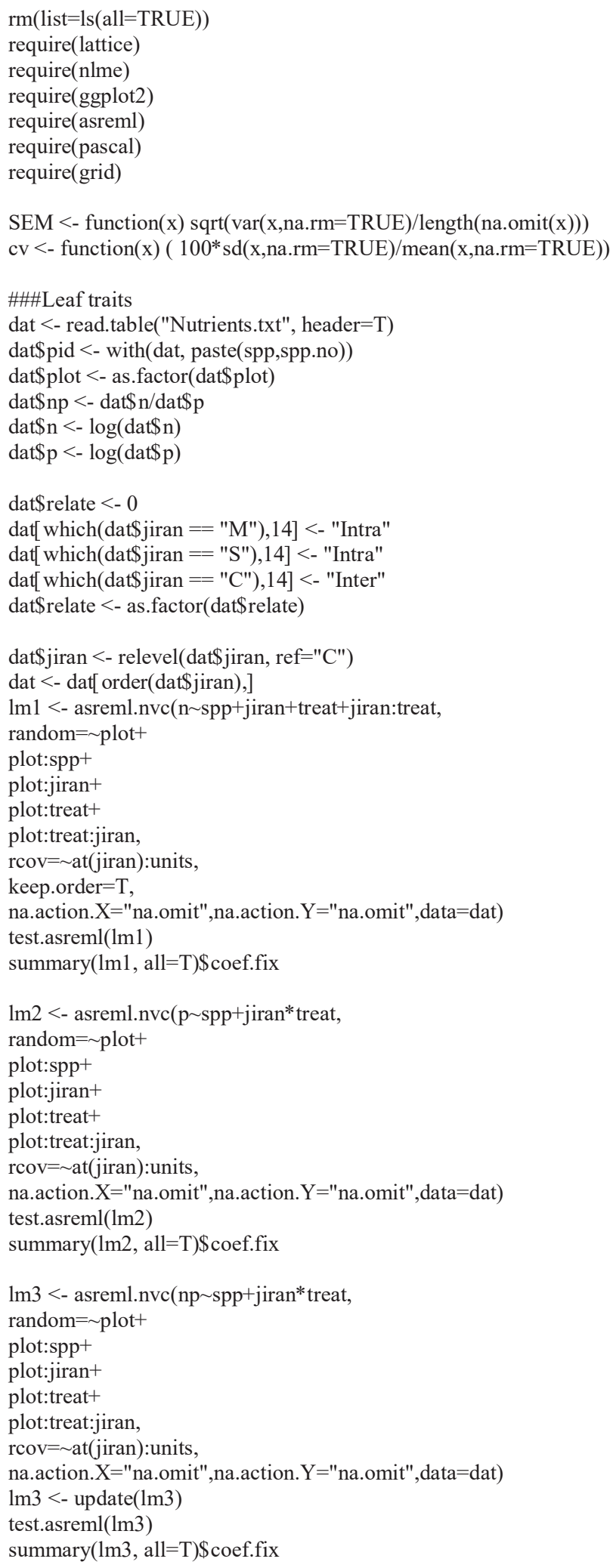

